\title{
Study of seasonal climatology and interannual variability over India and its subregions using a regional climate model (RegCM3)
}

\author{
P MAHARANA and A P DimRI* \\ School of Environmental Sciences, Jawaharlal Nehru University, New Delhi 110 06\%, India. \\ *Corresponding author.e-mail: apdimri@hotmail.com
}

The temporal and spatial variability of the various meteorological parameters over India and its different subregions is high. The Indian subcontinent is surrounded by the complex Himalayan topography in north and the vast oceans in the east, west and south. Such distributions have dominant influence over its climate and thus make the study more complex and challenging. In the present study, the climatology and interannual variability of basic meteorological fields over India and its six homogeneous monsoon subregions (as defined by Indian Institute of Tropical Meteorology (IITM) for all the four meteorological seasons) are analysed using the Regional Climate Model Version 3 (RegCM3). A 22year (1980-2001) simulation with RegCM3 is carried out to develop such understanding. The National Centre for Environmental Prediction/National Centre for Atmospheric Research, US (NCEP-NCAR) reanalysis 2 (NNRP2) is used as the initial and lateral boundary conditions. The main seasonal features and their variability are represented in model simulation. The temporal variation of precipitation, i.e., the mean annual cycle, is captured over complete India and its homogenous monsoon subregions. The model captured the contribution of seasonal precipitation to the total annual precipitation over India. The model showed variation in the precipitation contribution for some subregions to the total and seasonal precipitation over India. The correlation coefficient (CC) and difference between the coefficient of variation between model fields and the corresponding observations in percentage (COV) is calculated and compared. In most of the cases, the model could represent the magnitude but not the variability. The model processes are found to be more important than in the corresponding observations defining the variability. The model performs quite well over India in capturing the climatology and the meteorological process. The model shows good skills over the relevant subregions during a season.

\section{Introduction}

The Indian subcontinent is characterised by complexities associated with geography, topography, and differential land-use pattern. The western, eastern and southern parts of the subcontinent are surrounded by the Arabian Sea, Bay of Bengal and the Indian Ocean, respectively and the Himalaya is situated in the northern part and extends up to northeast India in the east. The land-use pattern is also not the same and varies from region to region over India. All of these combine to play a major role in deciding the climate of the Indian region and its subregions. The temporal and spatial variability of the precipitation is very high over the Indian region. The variability is often experienced in India as one part of the country is affected by heavy flood whereas the other part is suffering from drought at the same time. During summer (JuneSeptember), the Western Ghats and the northeast

Keywords. Interannual variability; homogeneous Indian subregions; correlation coefficient. 
region receive precipitation due to Indian summer monsoon (ISM) orographic interplay and the eastern Indian region (Orissa, Chhattisgarh and West Bengal) receives majority of precipitation due to the monsoon trough. The northeast monsoon contributes to major precipitation in southern India during the post-monsoon period (OctoberNovember) and Jammu and Kashmir and the northern Indian region receive precipitation during winter (December-February). The temporal and spatial variability of the ISM play a major role in deciding the Indian economy as around 55\% of the population still depends upon the summer monsoonal precipitation for agriculture. The winter time rain also plays a major role in the yield of winter crops over north India. The strategic planning and the policies related to monsoon also depend upon the monsoonal variability.

During the Indian winter, northern India receives precipitation due to eastward moving low pressure synoptic weather system originating from the Mediterranean Sea called the western disturbances (WDs): Indian winter monsoon (IWM) (Lang and Barros 2004; Dimri 2008; Dimri and Mohanty 2009; Dimri and Niyogi 2012). Dimri and Ganju (2007) used a regional climate model (RCM) to study the climatology and intraseasonal variability over the western Himalayas during winter. Dimri (2007) studied the mean circulation and energetic distribution during winter over the south-east Asia. ISM is primarily caused by the differential heating of landmass and ocean (Cadet 1979). The subcontinental topography and the surrounding oceans play a very important (combined dynamical and thermodynamical) role in influencing the monsoonal precipitation. Various researchers have worked on the interannual variability of ISM using the observational dataset. Mooley and Parthsarathy (1984) used the precipitation data from different rain gauge stations over India to study the variability of ISM and correlated it with the southern India oscillation index and sea surface temperature anomaly. Krishnamurthy and Shukla (2000) used the data gridded by Hartmann and Michelsen (1989) $\left(1^{0} \times 1^{0}\right)$ using 3700 rain gauge stations from India Meteorological Department (IMD) to study the interannual variability and intraseasonal variability of precipitation over India. Goswami and Ajaya Mohan (2001) used NCEP daily circulation data to study the interannual and intraseasonal variability of the ISM. Wang et al. (2001) analysed 50 years of NCEP-NCAR reanalysis dataset to study the ISM and western north Pacific summer monsoon. Their study shows a remarkable difference between the temporalspatial structures, relationships to El-Nino, and tele-connections between mid-latitude circulations. Kriplani et al. (2003), Dash et al. (2005) and
Shekhar and Dash (2005) have shown relation between snow cover over Himalayas, Europe, and Tibet and their relation with the ISM respectively. Dash et al. (2002) explain that each subregion is important because it has its own regional climatic characteristics and the precipitation analysis over these subregions should be studied separately. Their study included five different homogenous monsoon regions. Pattnayak et al. (2013) used a RCM to study the regional precipitation characteristic of the six homogenous monsoon regions; they also reported that the surplus moisture flux over the Arabian Sea causes the prolonged rainy season in the model. Lucas-Picher et al. (2011) studied the ability of four different regional climate models to reproduce the summer monsoon. Their study also includes the temporal variation of precipitation over five different river basins which represent five different regional climates within India. Ratna et al. (2010) have used a high resolution five member ensemble atmospheric general circulation model to study the ISM circulation and its interannual variability of precipitation. During the post-monsoon season Kumar and Kriplani (2004), Kumar et al. (2007) and Yadav (2012) extensively described the role of the northeast monsoon (NEM). So the ISM (June-September), NEM (October-November), and IWM (DecemberFebruary) play important roles in defining the spatial as well as temporal variability of the regional climate of the Indian subcontinent (Dash et al. 2006). Regional Climate Model Version 3.0 (RegCM3) has been widely used by the scientific community worldwide to study the climate change of a region (Mearns et al. 1995; Pal et al. 2004; Giorgi and Copolla 2007; Im et al. 2010), the circulation and precipitation pattern (Dash et al. 2006; Ratnam et al. 2009), and the seasonal variability (Seth et al. 2007). Afiesimama et al. (2006) and Sylla et al. (2009a, b) have conducted various experiments using RegCM3 over Africa and its subregions. Sylla studied the climatology, interannual variability of the rainfall, and the mean annual cycle over the African domain and its subregions. They reported that the model processes are more dominant in determining the rainfall variability than the initial and boundary conditions.

Various reanalyses are available at different horizontal resolutions. Different datasets are used for the preparation of the reanalysis data such as the stations, satellite, etc. Generally the establishment of stations over all regions is not possible due to various reasons, so during preparation of the reanalysis data different interpolation techniques are used to get the value over the data sparse region. The different reanalyses differ in algorithm from each other and the accuracy also depends upon the algorithms. The regional climate 
model is generally used to study a synoptic process or predictability of the future (Seth et al. 2007). The regional climate model generally dynamically downscales the reanalysis data for better representation of a process. So the use of regional climate model is useful for better understanding of the processes associated with the precipitation.

In the present study an attempt is made to understand the skill of RegCM3 over India and the six homogenous monsoon regions. To achieve the objective, the study of the climatology of different meteorological fields, the interannual variability, mean annual cycle, and different statistical analyses has been done for all the seasons. The uniqueness of the study is that it focuses on all the subregions and all the seasons whereas most of the earlier studies generally focused on only one season. The contribution of seasonal precipitation to the total annual precipitation as well as the contribution of each subregional precipitation to the total annual and seasonal precipitation over India is computed in percentages and quantified. In the following paragraphs, section 2 describes the experimental design, data, and methodology used in the study followed by detailed presentation and discussion based on the study in section 3 . Finally, section 4 summarises salient features of the study.

\section{Experimental design, dataset and methodology}

\subsection{Experimental design}

The regional climate model RegCM3 (Pal et al. 2007 ) is used to carry out the necessary simulations for the present study. The dynamical core of the RegCM3 is similar to the hydrostatic version of the dynamical core of MM5 (Grell et al. 1994). The model uses CCM3 radiation parameterization scheme (Kiehl et al. 1998). The surface physics, which includes role of vegetation and exchange of water vapour, momentum and energy between land surface and atmosphere performed using Biosphere-Atmosphere Transfer Scheme (BATS1E) (Dickinson et al. 1993); the surface scheme over the ocean (Zeng et al. 1997); and planetary boundary scheme developed by Holtslag and Boville (1993). Grell (1993) convective precipitation scheme is used with Fritch and Chappell closure assumptions. The elevation data is taken from United States Geological Survey (USGS) and the land use and vegetation data is taken from USGS Global Land Cover Characterization (GLCC). The sea surface temperature is taken from Global Sea Ice and Sea Surface Temperature (GISST) and analyses at the Hadley Centre for Climate
Prediction and Research, UK (Rayner et al. 1996). The model consists of 96 grid points along eastwest direction and 94 grid points along north-south direction with centre at $20^{\circ} \mathrm{N} 75^{\circ} \mathrm{E}$. The number of vertical model layers is chosen to be 18 . The horizontal resolution is $50 \mathrm{~km}$. This is a very large domain where the model can reproduce its own circulation pattern, so this horizontal resolution can still be useful to capture the circulation features along the domain and the spatial variability of precipitation and temperature. The simulation is done for 22 years (1980-2002) to study the climatology of different fields and interannual variability of precipitation over India and its subregions. The model integration is started from 1 November $(n-1)$, where $n$ is the starting year. The first month's simulation is considered as spin up time. The model domain of simulation is shown in figure 1 and model description is provided in table 1.

\subsection{Data used}

The model is forced with NNRP2 (Kanamitsu et al. 2004) as the initial and boundary conditions which is updated every $6 \mathrm{~h}$ to carry out the simulations. The high moisture representation of the ERA40 reanalysis and the spectral snow problem in the NNRP1 reanalysis which is related to the moisture diffusion and temperature on a pressure surface are improved in the NNRP2 reanalysis. These 22 years of simulation include the normal, deficit, as well as the excess rain years. The analysis of the 22 years of model output over India and its homogenous monsoon subregions will give a clear idea about the model performance over the above-mentioned region.

Four precipitation observational fields from Climate Research Unit (CRU) (TS2.1; Mitchell and Jones 2005), Asian Precipitation Highly Resolved Observational Data Integration Towards the Evaluation of Water Resources (APHRODITE-Yatagai et al. 2009) (APH hereafter), India Meteorological Department (IMD) gridded precipitation (Rajeevan and Bhate 2008) and Global Precipitation Climatology Project (GPCP-Adler et al. 2003) are used for validation of model details. The horizontal resolution of the CRU analysis is $0.5^{\circ} \times 0.5^{\circ}$. The monthly mean dataset is developed using the station data by anomaly interpolation approach over the whole globe. The APH daily data is developed using the station dataset over Asia, a new weighted mean interpolation method is used to put these data in $0.25^{\circ} \times 0.25^{\circ}$ grid. IMD used rain gauge station data to develop the $0.5^{\circ} \times 0.5^{\circ}$ gridded dataset over India; Shepherd's interpolation technique is used for this. The GPCP is a 


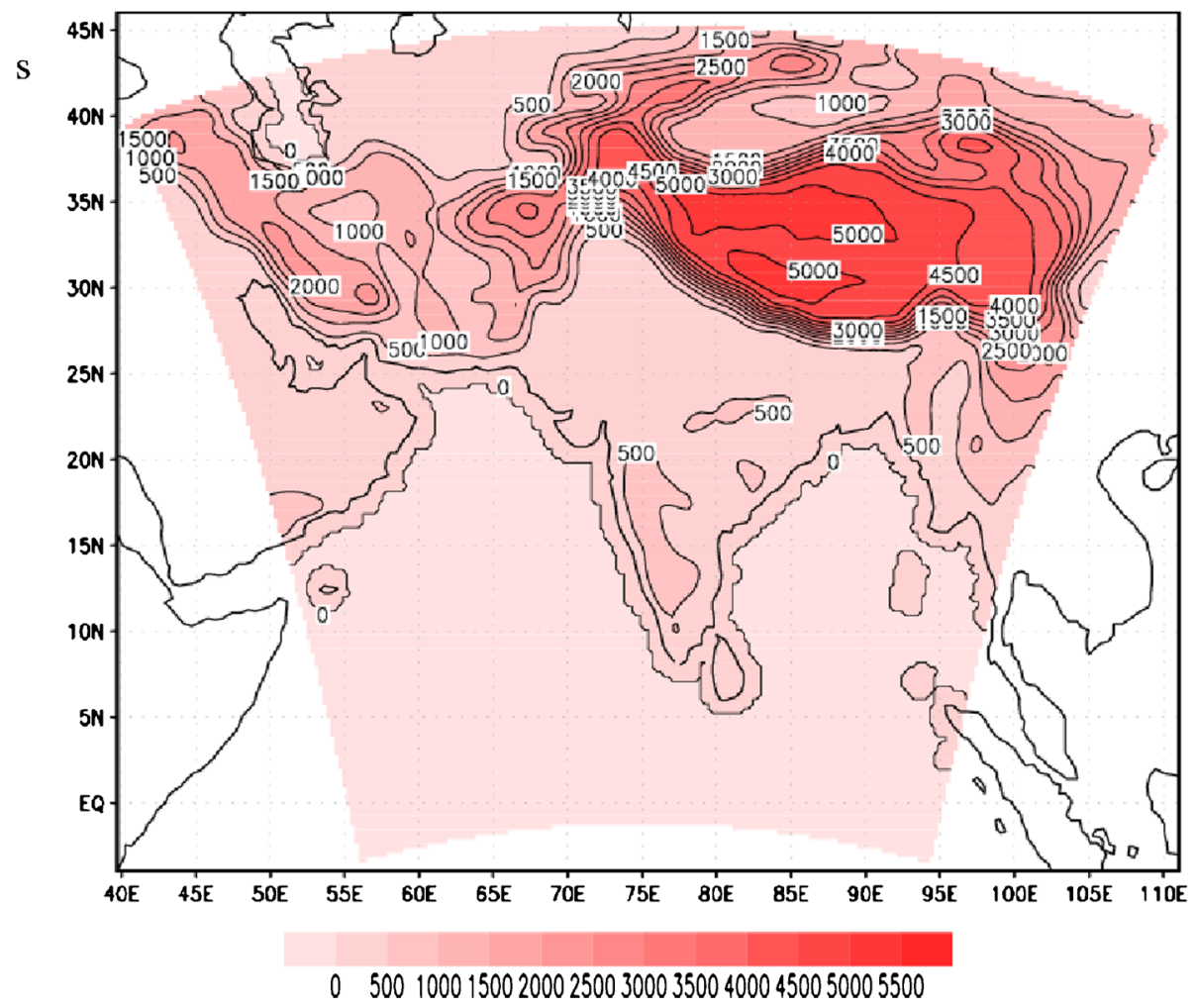

Figure 1. Model domain and topography used in RegCM3 simulation.

Table 1. Model description.

\begin{tabular}{|c|c|}
\hline Model & RegCM3 \\
\hline Simulation period & $1980-2001$ \\
\hline Dynamics & MM5 hydrostatic (Grell et al. 1994) \\
\hline Main prognostic variables & $\mathrm{u}, \mathrm{v}, \mathrm{t}, \mathrm{px}, \mathrm{ts}$ \\
\hline Central point of domain & Longitude: $75^{\circ} \mathrm{N}$ latitude: $20^{\circ} \mathrm{E}$ \\
\hline Number of horizontal grid points & 96,94 grid points for $\mathrm{x}, \mathrm{y}$ respectively \\
\hline Horizontal grid distance & $60 \mathrm{~km}$ \\
\hline Number of vertical levels & $18 \sigma$ levels \\
\hline Horizontal grid scheme & Arakawa-Lamb B grid staggering \\
\hline Time integration scheme & Split explicit \\
\hline Lateral boundary conditions & NNRP2 \\
\hline Radiation scheme & CCM3 (Kiehl et al. 1998) \\
\hline Planetary boundary layer parameterization schemes & Non-local, counter-gradient (Holtslag and Boville 1993) \\
\hline Convective precipitation scheme & Grell (Grell 1993), Fristch and Chappell closure assumptions \\
\hline Soil model & High resolution soil model (Dickinson 1984) \\
\hline Topography & USGS \\
\hline Surface parameters & BATS1E (Dickinson et al. 1993) \\
\hline $\mathrm{SST}$ & GISST \\
\hline
\end{tabular}

merged analysis interpolation of the rain gauge data and satellite data to $2.5^{\circ} \times 2.5^{\circ}$ grid over globe. Two temperature observations from CRU and IMD temperature gridded dataset are used to validate the model temperatures. The validation of the model wind is done with NNRP2 winds. The NNRP2 monthly mean rain rate is also used to validate the interannual variability of the model simulation. The reason behind choosing four precipitation and two temperature observational data is to show the representation of the seasonal precipitation and temperature climatology in different subregions of India in different observational datasets and to show the robustness of the different interpolation techniques and the algorithm used to prepare different observational datasets. 


\subsection{Methodology}

The whole year is classified meteorologically into four seasons, viz., winter (December-February); premonsoon (March-May); summer monsoon (JuneSeptember) and post-monsoon (October-November). The six homogeneous monsoon subregions of India as defined by the IITM, Pune, India (www.tropmet.res.in) are considered in this study (figure 2). These six subregions are southern peninsular India (SPI), west-central India (WCI), northwest India (NWI), northeast India (NEI), Hilly Region (Hilly) and the central northeast (CNE). All regions are considered for the study since so far no detailed seasonal analysis is available over these regions.

For seasonal precipitation analysis over India and its six subregions, standardized anomaly of model and observed precipitation is determined for every year by dividing its anomaly with the corresponding standard deviation. Subsequently, corresponding coefficient of variation of the model and observation is determined by dividing the corresponding standard deviations with their climatological mean. The difference between this coefficient of variation between the model and observation (model minus observation) in percentage is considered as an error of statistical variability (and hereafter called COV). The performance of the model is evaluated using the Equitable Threat Score (ETS) and Taylor diagram. Apart from this, mean annual cycle is analysed by calculating mean of the monthly precipitation over India and the six homogenous subregions. In addition, total precipitation is quantified by multiplying the total area with precipitation (in metres) over India and its subregions (the area of India and the other subregions is taken from the Census-1991). Similarly the contribution of precipitation by each season(s) and subregion(s) to total Indian precipitation is estimated. Also, contribution of subregions in the total seasonal precipitation over India is calculated.

\section{Results and discussion}

This section discusses climatology of different fields, such as precipitation, surface air temperature, winds at different vertical pressure levels, mean annual cycle, and interannual variability of precipitation with main focus on IWM and ISM.

\subsection{Seasonal mean climatology}

In this section, the simulated climatological fields and corresponding observational fields are discussed to assess whether the model is able to represent the regional climate of subregions for different seasons. The climatological fields of the different meteorological parameters are shown on their respective grids without interpolation into common

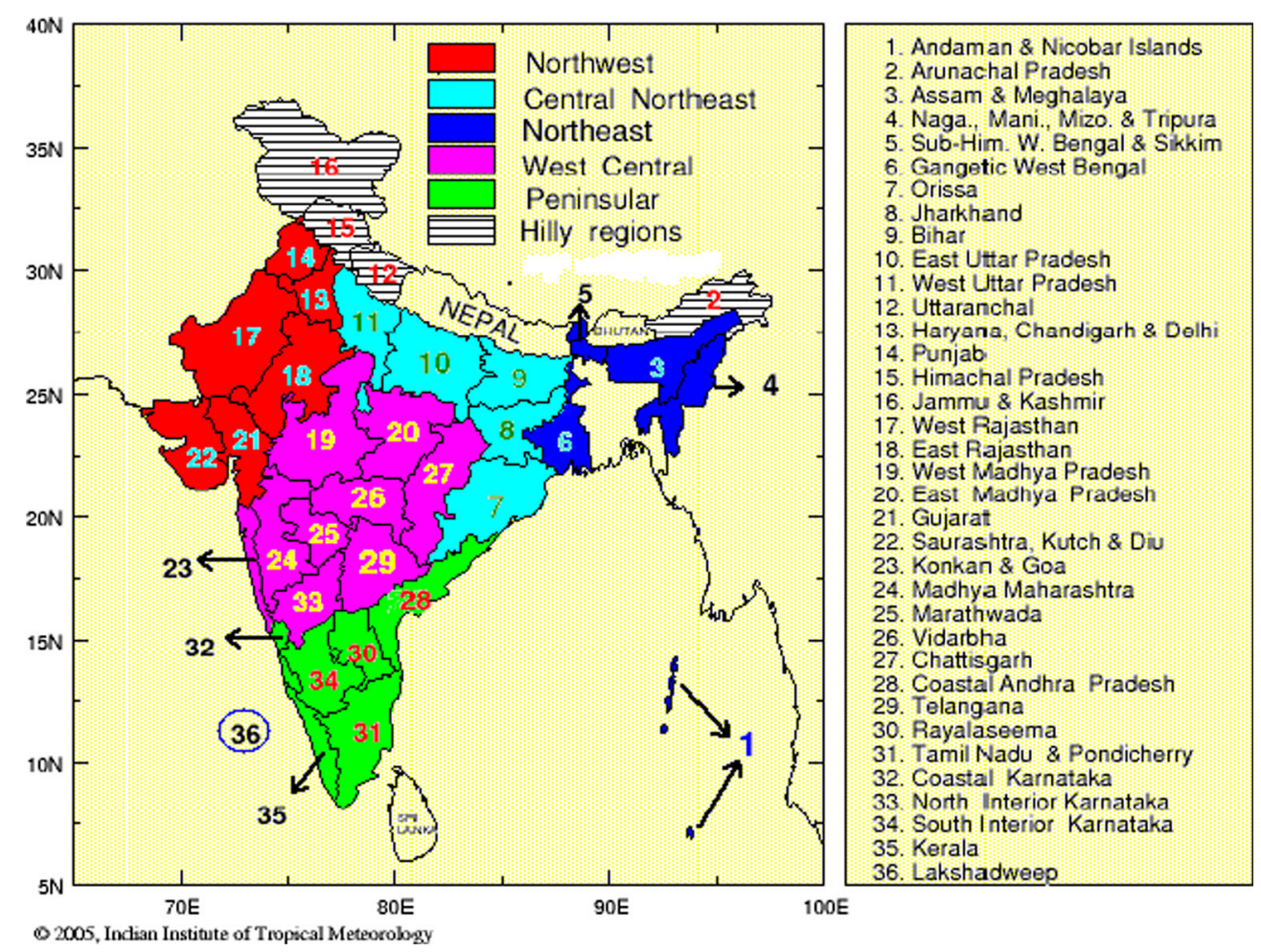

Figure 2. Six homogenous monsoon regions of India. 
grid. But before calculation of the model bias, the observational dataset are interpolated into model grids.

\subsubsection{Winds at 850, 500 and $200 \mathrm{hPa}$}

Seasonal average wind bias (model minus observation) at different pressure levels is presented in figure 3. Figures pertaining to seasonal average wind of model and observation are not presented separately and only prominent seasonal wind features are discussed. Figure $3(\mathrm{a}-\mathrm{c})$, illustrates wind features at 200, 500, and $850 \mathrm{hPa}$, respectively during winter. First of all, the model could represent the upper level southward shift of subtropical westerly jet (STWJ) at $200 \mathrm{hPa}$. This is one of the important winter seasonal wind features which brings in enormous amount of precipitation in association with WDs as it provides necessary divergence for the intensification of the WDs. At surface, $850 \mathrm{hPa}$, the model too represents westerly winds coming from the middle-east to the Himalayas having strength ranging from 4 to $8 \mathrm{~m} / \mathrm{s}$. This wind flow brings in moisture from the Arabian Sea during winter which provides suitable moisture incursion for increased precipitation in association with WDs (figure not shown). The winter time circulation features are captured but the model shows higher strength of westerly winds over the Pakistan region by 2 to $6 \mathrm{~m} / \mathrm{s}$ (figure 3c). The major circulation feature during pre-monsoon period is the STWJ at middle and upper atmosphere, which is captured by the model. It has shifted its position to north above Himalayas compared to its position during winter over Indo-Gangetic plain (figure not shown). The model overestimates the wind by $2-4 \mathrm{~m} / \mathrm{s}$ in the $850 \mathrm{hPa}$ level (figure 3f). The summer monsoonal circulation process such as the cross equatorial flow, which bends to the right due to the coriolis forces and becomes the Findlater Jet. This carries moisture from the Arabian Sea to the Indian landmass and causes the precipitation. All the features are captured by the model along with the monsoonal trough region in the lower level at $850 \mathrm{hPa}$. At the upper level, major circulation features such as tropical easterly jet (TEJ), STWJ along with the major monsoonal features such as the wind reversal at 850 and $200 \mathrm{hPa}$ are well captured by the model (figure not shown). Figure $3(\mathrm{~g})$ shows the Findlater jet; its strength position and spatial extension are well captured by the model with very less bias at $850 \mathrm{hPa}$. Tropical easterly and subtropical westerly jets are overestimated in magnitude by $4-7 \mathrm{~m} / \mathrm{s}$ and $6-7 \mathrm{~m} / \mathrm{s}$, respectively (figure $3 \mathrm{i}$ ). The model shows very weak NEM circulation (figure not shown). Figure 3(l) represents the underestimation of the wind over south India.

\subsubsection{Precipitation}

Figure 4(a-d) shows the seasonal average precipitation bias during winter for APH, GPCP, IMD, and CRU dataset respectively. Similarly, figure $4(\mathrm{e}-\mathrm{p})$ depicts the same for pre-monsoon, monsoon, and post-monsoon for the above described observational dataset, respectively. The winter time precipitation over north India is mainly caused by the eastward moving WDs. The precipitation mostly occurs along the Himalayas because it does not allow disturbances to cross and causes the orographic precipitation. The different observational datasets represent the winter time precipitation over the Himalayas with a little deviation from one another. The model is able to capture the spatial pattern of the winter time precipitation along the Himalayas (figure not shown). The model overestimates the precipitation by $1-4 \mathrm{~mm} /$ day over the northwest Jammu and Kashmir (figure 4a, b and d) except in IMD (figure 4c) where the spatial extension is less. During spring, the Himalayas along its stretch from west to east, gets precipitation as represented in the different observational datasets. The model captures precipitation over India, which occurs in the Himalayas from Jammu and Kashmir to northeast (figure not shown). This may be attributed to the moisture in the STWJ and its interaction with the complex orography of Himalayas and also the convection due to the higher temperature or pre-monsoon thunderstorm over this region. The model shows a wet bias of $2-5 \mathrm{~mm} /$ day and above over a few regions of the Himalayas and the northeast region (figure $4 \mathrm{e}-$ h). During the ISM, the Findlater jet at $850 \mathrm{hPa}$ brings in moisture to the Indian landmass. The interaction of the southwesterly with the Western Ghats results in heavy precipitation over this region; whereas the leeward side of the Western Ghats gets lesser precipitation. As the southwesterly advances, it collects the moisture from the Bay of Bengal and causes heavy precipitation over northeast India. Central India gets rainfall due to the landfall of the monsoon depression originating in the Bay of Bengal. Northwestern India hardly gets rain during this period so it is a water scarce region. The summer time spatial distribution of the precipitation is well represented in all the observational datasets with major precipitation peaks at the Western Ghats and northeast India along with the rainfall activity in the monsoon core zone. The model being at finer resolution is able to resolve the topographic interaction of the wind, so the simulation rightly reproduces the higher rainfall over the Western Ghats and northeast (figure not shown). Figure 4(i-l) shows that the region along the Himalayas has dry bias of $2-5 \mathrm{~mm} /$ day and over central India by $1-3 \mathrm{~mm} /$ day. The eastern 
(a) Bias_200hPa_DJF
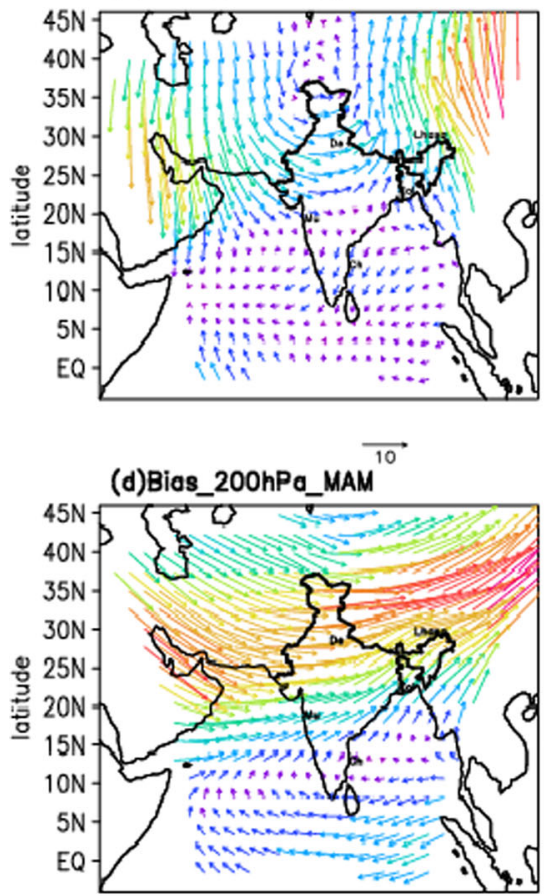

$\overrightarrow{10}$
(b)Bios_500hPa_DJF
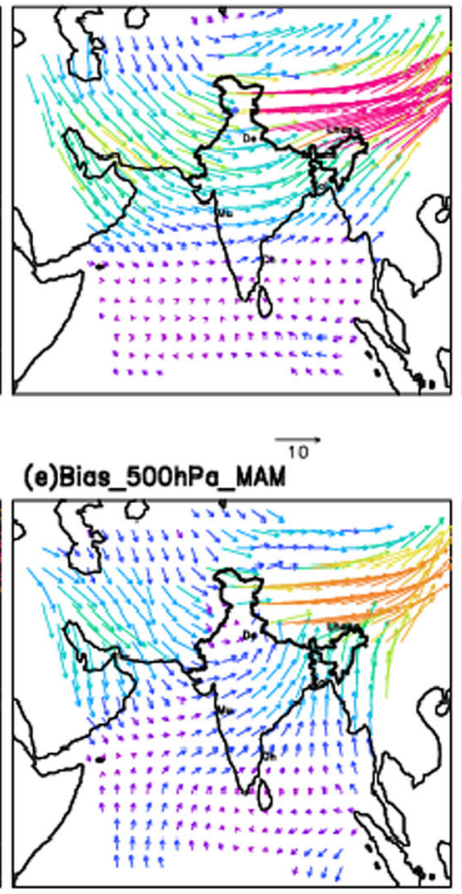

$\overrightarrow{10}$
(c)Bios_850hPa_DJF

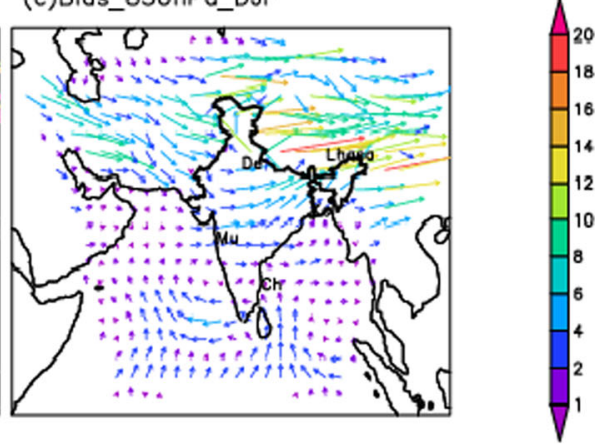

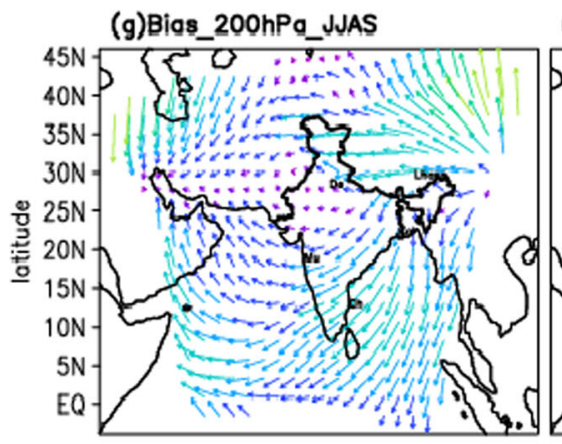

(h)Bigs_500hPa_JJAS

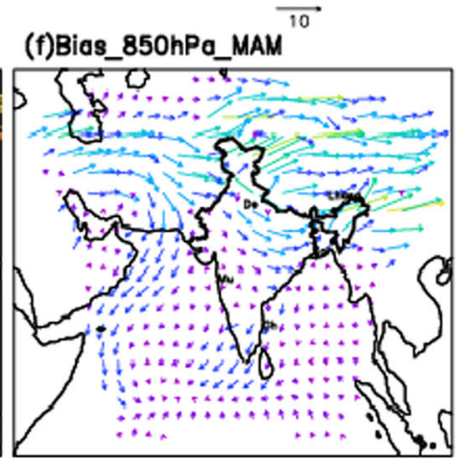

$\overrightarrow{10}$

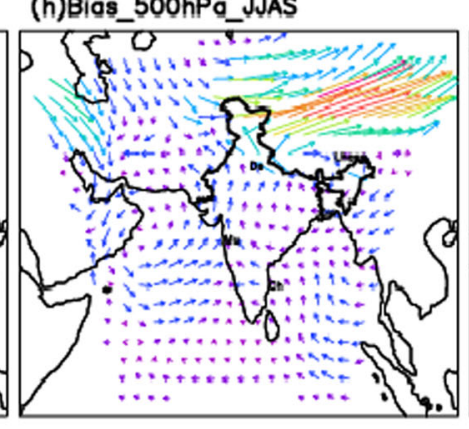

(i)Bigs_850hPa_JJAS

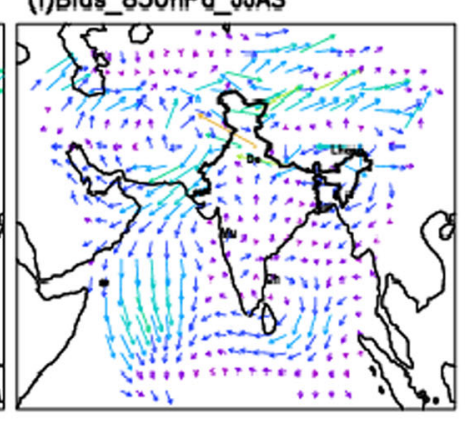

10

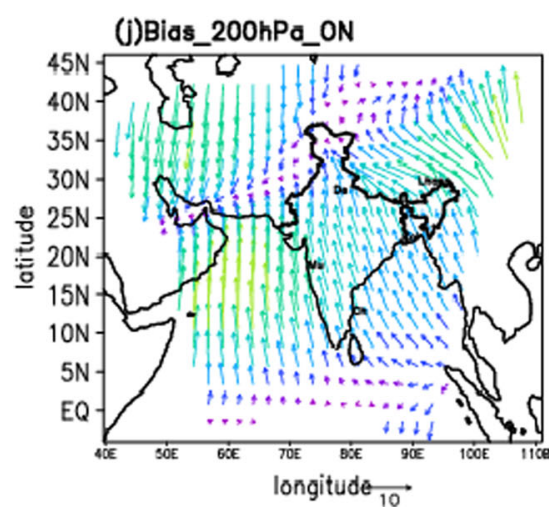

(k)Bias_500hPa_ON

10

$\overrightarrow{10}$

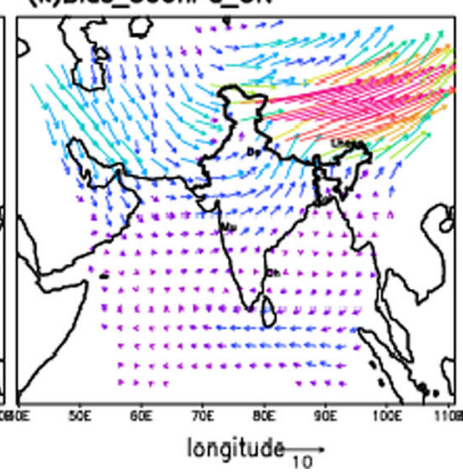

(1)Bias_850hPa_ON

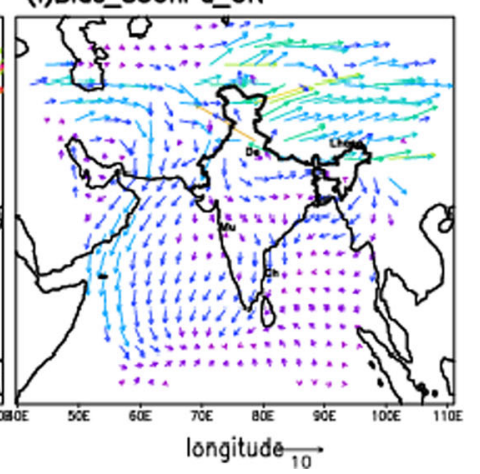

Figure 3. Seasonal average wind bias at 850, 500 and $200 \mathrm{hPa}$.

Rajasthan and the Indo-Gangetic plain regions show a wet bias of 1-2 mm/day and dry bias over the Western Ghats and southern peninsular India. This suggests that the precipitation over central India or the monsoon core zone is less in the model.
The possible reasons may be, the excessive loss of moisture in the form of precipitation over the Western Ghats and the higher temperature over the Bay of Bengal, which reduces the moisture content of the atmosphere above the sea. So the monsoon 

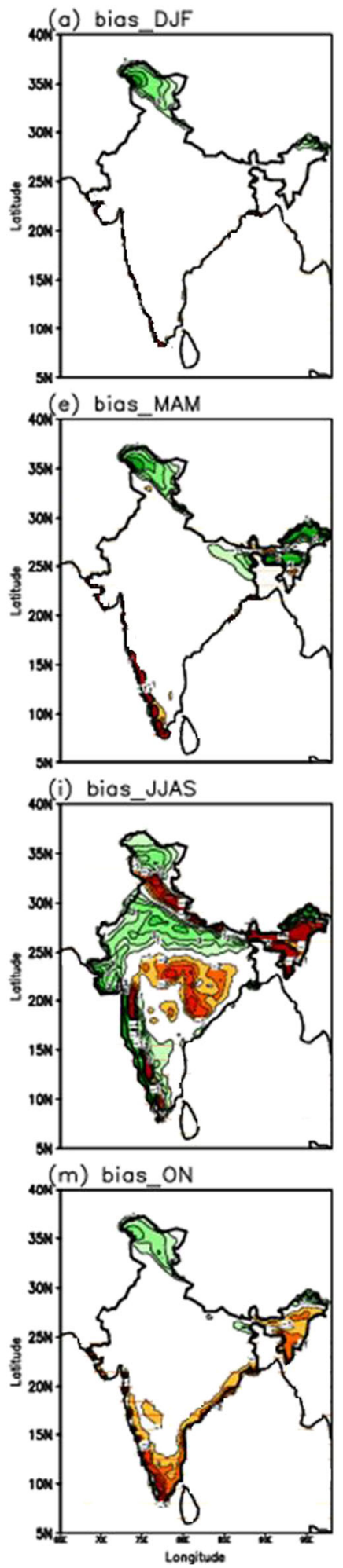

(b) bias DJF

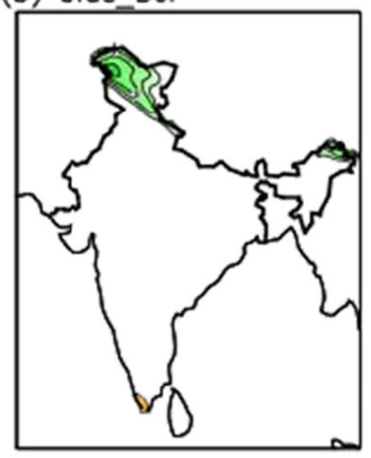

(f) bias_MAM

(c) bias DJF

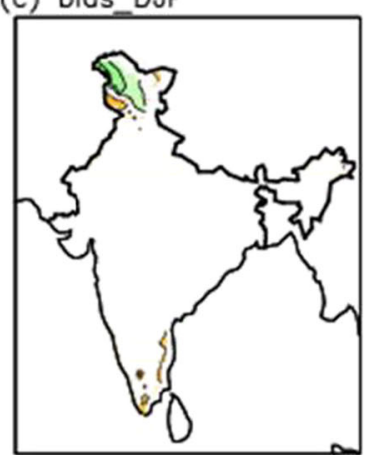

(g) bias_MAM

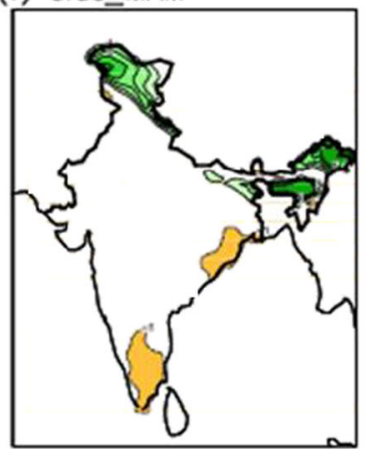

(j) bios_JJAS

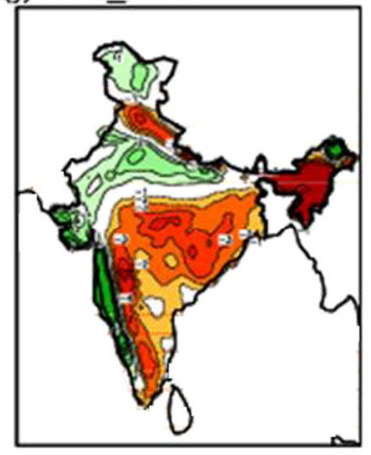

(n) bias_ON
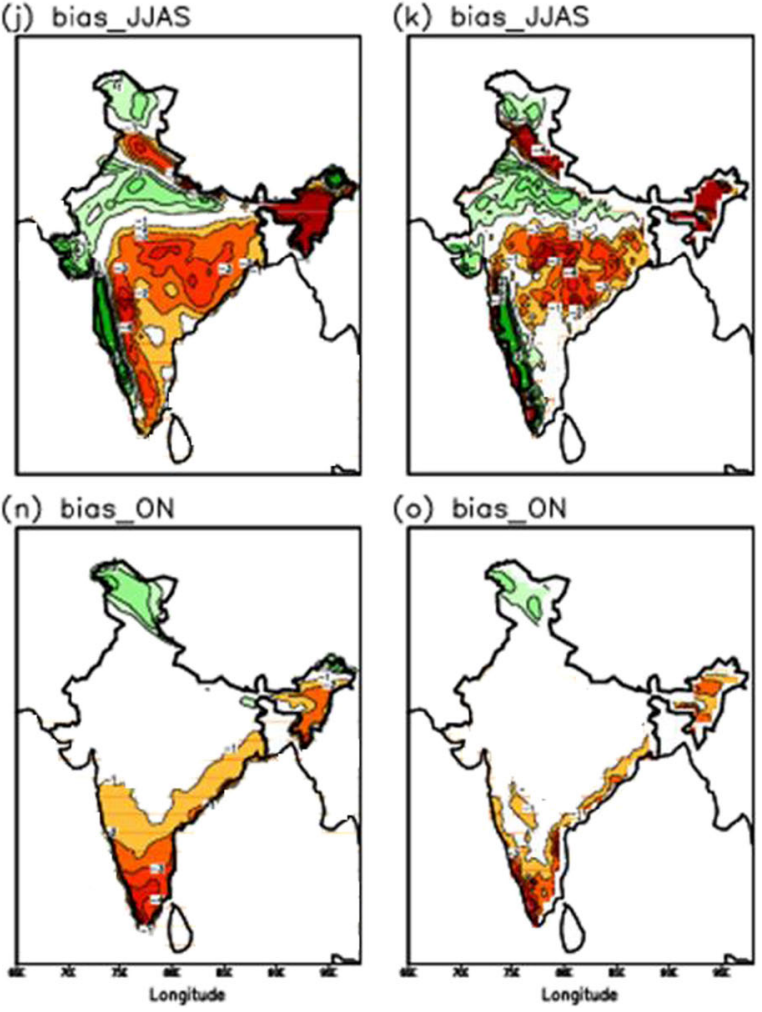

(o) bias_ON

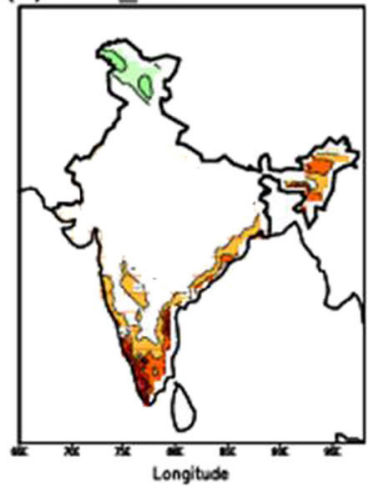

(d) bias_DJF

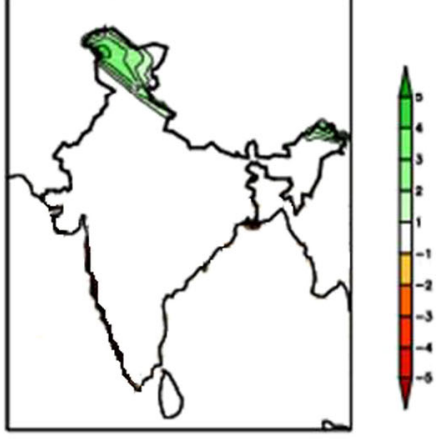

(h) bias_MAM

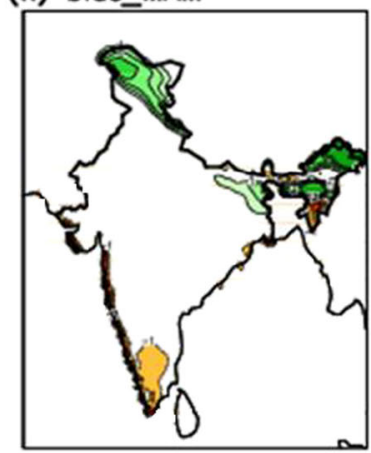

(I) bios_JJAS

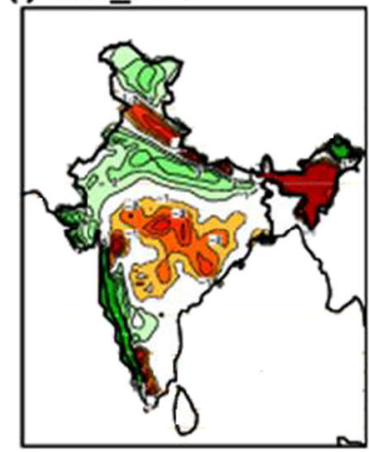

(p) bias_ON

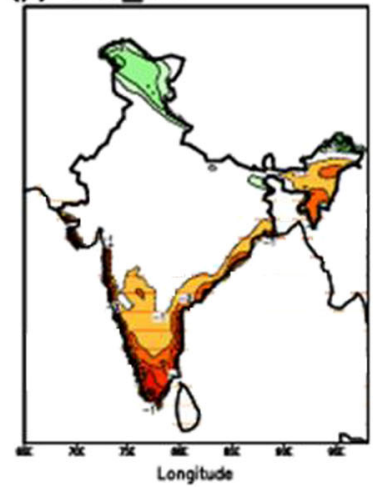

Figure 4. Seasonal average precipitation bias (mm/day) for APH (left hand panel) GPCP (right to left hand panel) IMD (left to right hand panel) and CRU (left hand panel).

disturbances originating at the Bay of Bengal do not have high moisture content. The unavailability of high moisture contributes to less rainfall over the monsoon core region in the simulation. Similar results were reported by Lucas-Picher et al. (2011). During the post-monsoon season the northeast monsoon gets activated, which causes precipitation over southern India. Since the NEM circulation is 
very weak the model precipitation is also less and the model shows a dry bias $2-3 \mathrm{~mm} /$ day over south India during this period (figure $4 \mathrm{~m}-\mathrm{p}$ ).

\subsubsection{Surface air temperature}

Figure 5(a and b) shows the winter seasonal average air temperature bias with IMD and CRU respectively. Similarly, figure $5(\mathrm{c}-\mathrm{h})$ depicts the seasonal average air temperature bias for pre-monsoon, monsoon, and post-monsoon for the above-described observational dataset, respectively. During winter (December-February), the model simulates maximum mean temperature of about 20 to $24^{\circ} \mathrm{C}$ over south India, about $8-16^{\circ} \mathrm{C}$ over north India and negative temperatures over the Himalayas (figure not shown). The model simulates the spatial distribution of temperature quite well over the Indian landmass. The simulation shows cold bias of about $4^{\circ} \mathrm{C}$ over the Himalayas and 1 to $2^{\circ} \mathrm{C}$ over southern India (figure $5 \mathrm{a}$ and b). During pre-monsoon (March-May), the IMD and CRU observations indicate mean temperature of around $24^{\circ} \mathrm{C}$ over north India and of $30^{\circ} \mathrm{C}$ over south peninsular India. The model simulated climatology shows higher temperature of $30^{\circ} \mathrm{C}$ over the Rajasthan region and lower of $20-24^{\circ} \mathrm{C}$ over peninsular India (figure not shown). The cold bias over peninsular India ranges from $2-5^{\circ} \mathrm{C}$, warm bias over Rajasthan region ranging from $1-3^{\circ} \mathrm{C}$ is observed (figure $5 \mathrm{c}$ and $\mathrm{d}$ ). During summer, the intertropical convergence zone (ITCZ) migrates over northern India and the high temperature belt shifts to north India. The temperature maximum (more than $30^{\circ} \mathrm{C}$ ) is observed over north India and extends from Thar Desert region up to the Gangetic plain (figure not shown). The model captures this heat low over north India but the spatial extent up to the Gangetic plain is not captured. The model underestimates the temperature during the summer monsoon season. It shows cold bias of $2-5^{\circ} \mathrm{C}$ over India (figure $5 \mathrm{e}$ and $\mathrm{f}$ ). During postmonsoon, due to the southward shift of the ITCZ the temperature belt also shifts southward. The bias plot (figure $5 \mathrm{~g}$ and $\mathrm{h}$ ) shows cold bias ranging from $4-6^{\circ} \mathrm{C}$ over the Himalayas and $1-3^{\circ} \mathrm{C}$ over central India and south India. This implies that the Indian region in model environment cools faster after the monsoonal activity. The higher rainfall in the model leads to wet surface conditions over the Indian landmass and its evaporation leads to lesser surface temperature and this may be the possible reason for the underestimation of temperature by the model. In the mean annual scale, the model temperature rises slowly to the maximum value during summer but after that it cools faster in the post-monsoon period. This results in the lower temperature gradient between the land and sea during the post-monsoon period. The higher sea temperature decreases the moisture availability over Bay of Bengal. This ultimately leads to the weak northeast monsoon and less precipitation over the southern part of India. Figure $4(\mathrm{~m}-\mathrm{p})$ shows the dry bias over the southern Indian region.

\subsubsection{Outgoing longwave radiation}

For simple understanding, the outgoing longwave radiation (OLR) shows the inverse of cloud cover, i.e., more the OLR, lesser the cloud cover and less convection and vice-versa. Figure 6(a-l) represents the seasonal average OLR of the model simulation, its corresponding observation and its respective bias. During winter, the model is able to capture the OLR over the Jammu and Kashmir region well (figure $6 \mathrm{a}$ and $\mathrm{b}$ ). The low value of OLR means high cloud condition over the Himalayan region which may lead to high precipitation over this region. The winter time temperature over the Himalayas is very less to support convection over these regions. The winter time rain is generally caused due to the large scale flow of winter disturbances. Since the circulation is strong in the model, more moisture reaches the Himalayas. The moisture containing flow and the topography interact to form clouds as a result of which this region shows low value of OLR in the bias (figure 6c). During the pre-monsoon period, the temperature starts to increase over the Himalayas. The rising temperature over this region causes surface evaporation. The rising moisture laden air forms convective clouds and hence shows low value of OLR along the Himalayan region. So the Himalayan region gets rainfall during the pre-monsoon period and the model captures this phenomenon (figure $6 \mathrm{~d}$ and e). Figure 6(f) illustrates negative bias over the Himalayan region which implies that the model shows more intense clouding over the Himalayan region and hence more precipitation. As discussed earlier, during summer, the model sheds most of its moisture in the Western Ghats region and the higher temperature over the Bay of Bengal makes the model environment dry over the sea. This is reflected in the model with low OLR over the Western Ghats and higher OLR over the monsoon core zone (figure 6g). The spatial distribution of the OLR during the summer is captured by the model. The interaction of moisture laden airmass with the Western Ghats and landfall of the monsoon depression causing convective activity over the monsoon core zone can be seen in the observational dataset with less OLR over this region (figure 6h). Figure 6(i) depicts the negative bias of OLR over the Himalayan and Western 
(a) bias_DJF
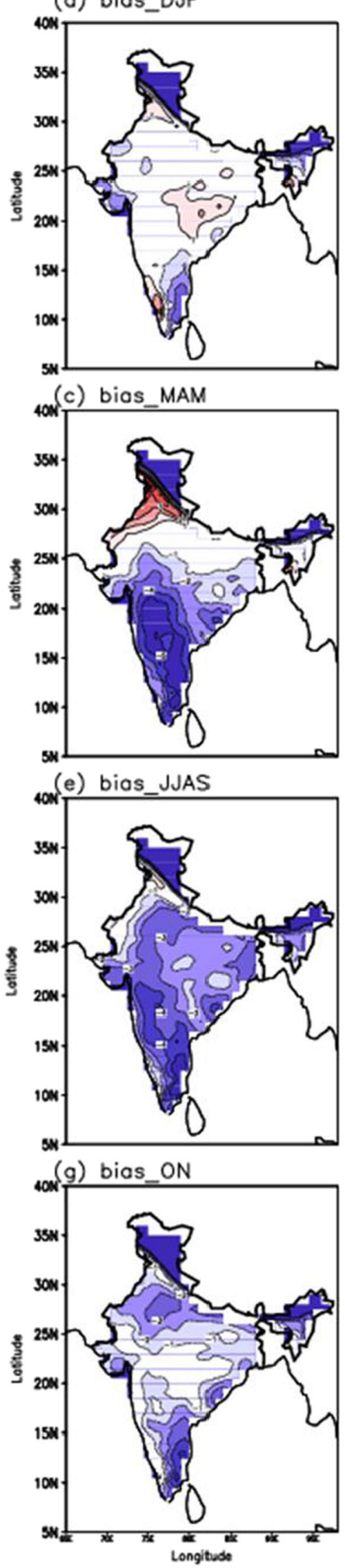

(b) bios_DJF

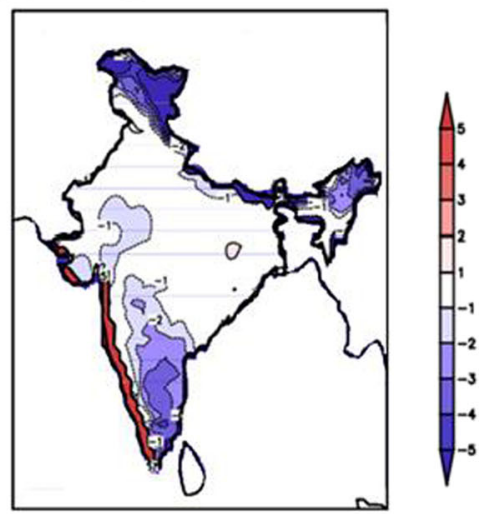

(d) bios_MAM

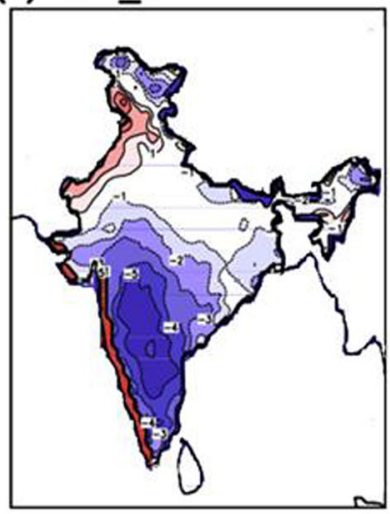

(f) bias_JJAS

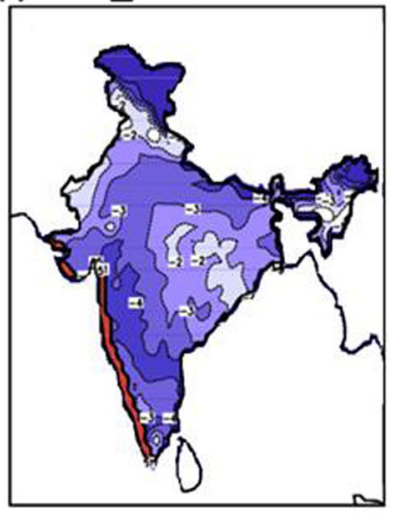

(h) bias_ON

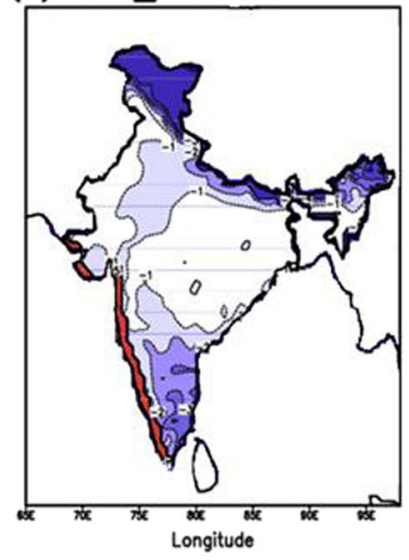

Figure 5. Seasonal average temperature bias $\left({ }^{\circ} \mathrm{C}\right)$ for IMD (left hand panel) and CRU (right hand panel). 
(a) Model (DJF)
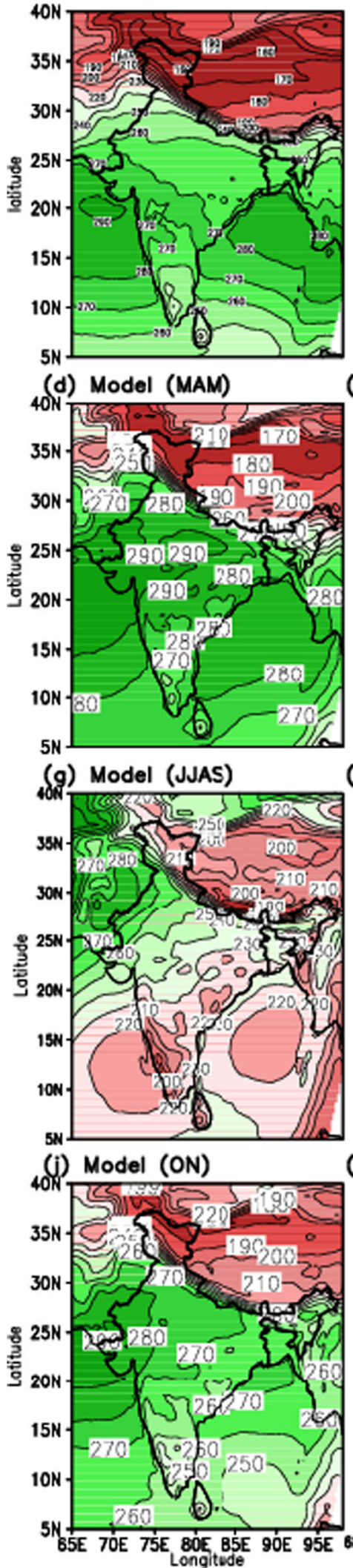

(b) Observation (DJF)

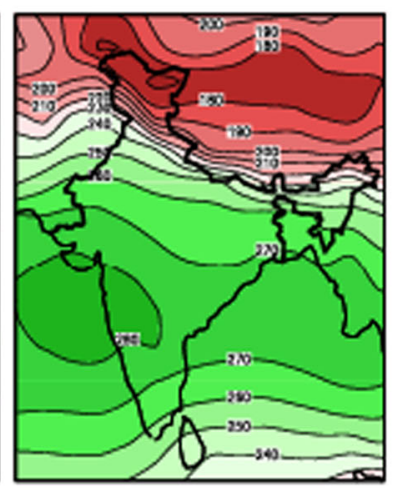

(e) Observation (MAM)

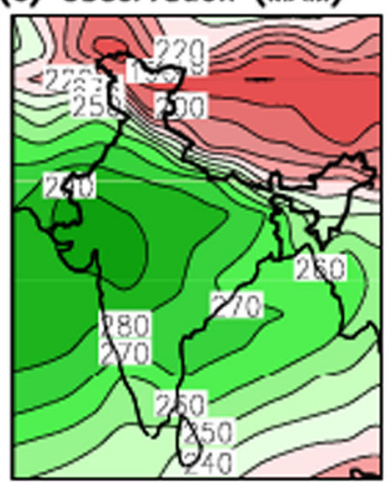

(h) Observation (JJAS)

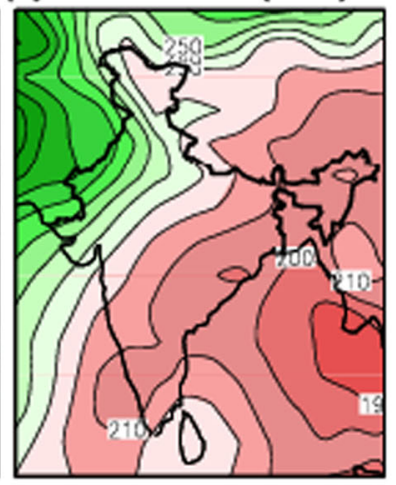

(k) Observation (ON)

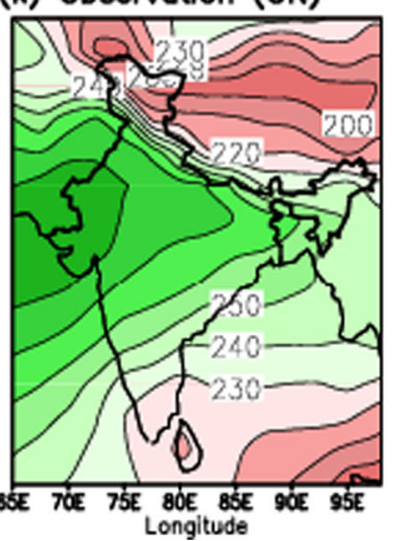

(c) Bios (Model-Observation)
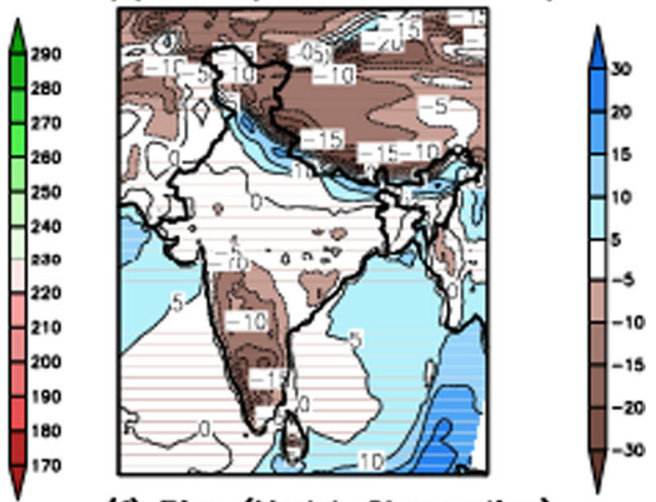

(f) Bias (Model-Observation)

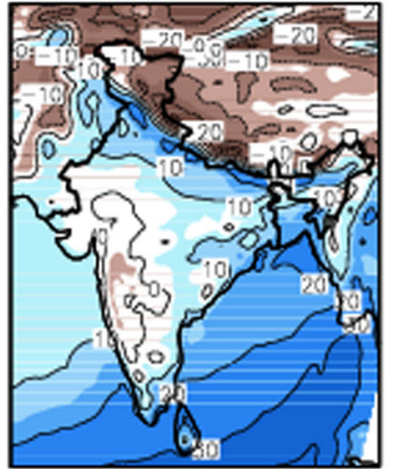

(i) Bias (Model-observation)

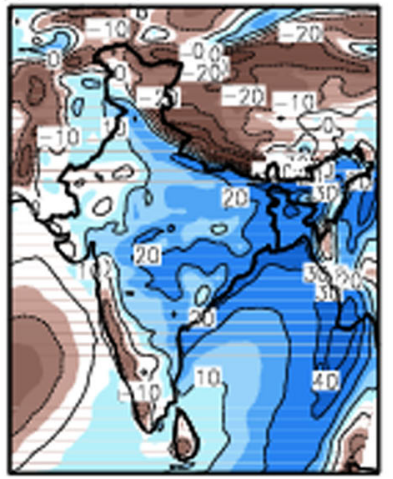

(I) Blas (Model-observation)

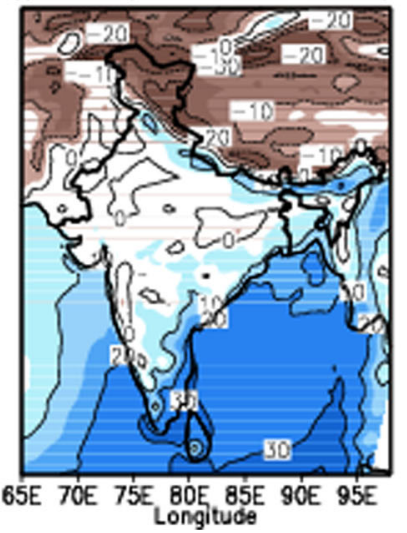

Figure 6. Seasonal average OLR of model, corresponding observation and their bias. 
Ghats region. It suggests that the major precipitation peak areas, where orographic precipitation plays a major part, show a negative bias of OLR or dense clouding. These dense convective clouds cause more intense precipitation over these regions in the model as compared to the observational dataset. During the post-monsoon period, the OLR is high over southern India in the model compared to the observation (figure $6 \mathrm{j}$ and $\mathrm{k}$ ). The bias over the southern India shows positive value, which means less convection over this region. This is due to the low temperature in the model compared to the respective observational analysis. As already discussed, the model is not able to capture the northeast monsoon well; here also the model could not exactly replicate the OLR conditions associated with clouding.

\subsection{Mean annual cycle of precipitation}

The mean annual cycle of the model and observed precipitation over the whole of India and its six homogenous subregions is shown in figure 7 . This explains the temporal variability of the precipitation. It illustrates that India gets the majority of its annual precipitation during the summer monsoon period (June-September). The precipitation starts increasing with the advancement of the monsoon from June which peaks by August due to the northward migration of the monsoon across the country. The monsoon retreats from September onwards and precipitation too diminishes after that. The overall pattern of the mean annual cycle is captured by the model. The comparison of the model with corresponding different observations (figure 7a), shows a good agreement with the APH and CRU, but is underestimated with IMD and GPCP. GPCP shows the highest magnitude during this period. The mean annual cycle is examined for different subregions. Over CNE region (figure $7 \mathrm{~b}$ ), the model is able to capture the pattern of the mean annual cycle of the precipitation. The magnitude is closer to the APH and CRU observations, whereas overestimated when compared with GPCP and IMD. Over the hilly region (figure $7 \mathrm{c}$ ), the model is unable to capture the cycle of annual precipitation and most importantly shows wide deviation during the ISM precipitation pattern. In the model environment, this region gets precipitation during winter (DecemberFebruary) and spring (March-May). The model is able to capture the precipitation due to WDs during winter and is found in good agreement with the IMD data. Only IMD observation shows this feature, may be due to better representation of precipitation gauges over the Indian region. Over the NEI (figure $7 \mathrm{~d}$ ) the model shows lead in precipitation cycle and so is unable to capture the pattern. IMD observation shows highest precipitation over this region. In the case of NWI subregion (figure 7e), the model could capture the pattern of mean annual cycle of precipitation but with slightly higher magnitude during August-September. Over SPI subregion (figure $7 \mathrm{f}$ ) two precipitation peaks during June-July and October-November are observed. The model is able to capture peak during ISM but could not capture peak during NEM. In case of WCI subregion (figure $7 \mathrm{~g}$ ) the pattern is well captured by the model though with lower magnitude of precipitation when compared with the corresponding observations.

\subsection{Interannual variability}

In the present section the interannual variability in standardized anomalies in model and corresponding observations averaged over the Indian and six homogeneous subregions (CNE, hilly, NEI, NWI, SPI and WCI) for four seasons (DecemberFebruary, March-May, June-September, OctoberNovember) are analysed. The results pertaining to the most relevant regions during a season are shown and discussed (the standardized anomaly for other regions for different seasons are not shown). The hilly region is considered for the analysis of winter and pre-monsoon. The whole Indian landmass, CNE and WCI subregions are considered during ISM and SPI is taken for the study during post-monsoon period. The reason behind choosing these regions for the study is that the hilly region gets precipitation during winter and pre-monsoon period. The whole of India receives precipitation during the ISM. The CNE and WCI are the subregions which form the monsoon core region where landfall of the monsoon depression plays a major role in the precipitation over these regions during summer. Southern India gets precipitation because of NEM during the post-monsoon season.

The interannual variability of precipitation in standardized anomaly in model and corresponding observations over India and different subregions is represented in figure $8(\mathrm{a}-\mathrm{f})$. Table 2 represents the $\mathrm{CC}$ between averaged precipitation over India and its six homogenous monsoon regions in different seasons and the COV. The CCs at $90 \%$ significance level is calculated and it was found that the CC value more than 0.3 and more are significant. During winter (December-February), the CCs of the model with different observations over hilly region varies as $-0.2(\mathrm{APH}), 0.6(\mathrm{CRU}), 0.8(\mathrm{CRU})$ and 0.6 (IMD).

Similarly the COV for different observational dataset ranges as $-10.2(\mathrm{APH}),-14.9$ (CRU), -3.8 (GPCP) and -15.8 (IMD) (table 2). 

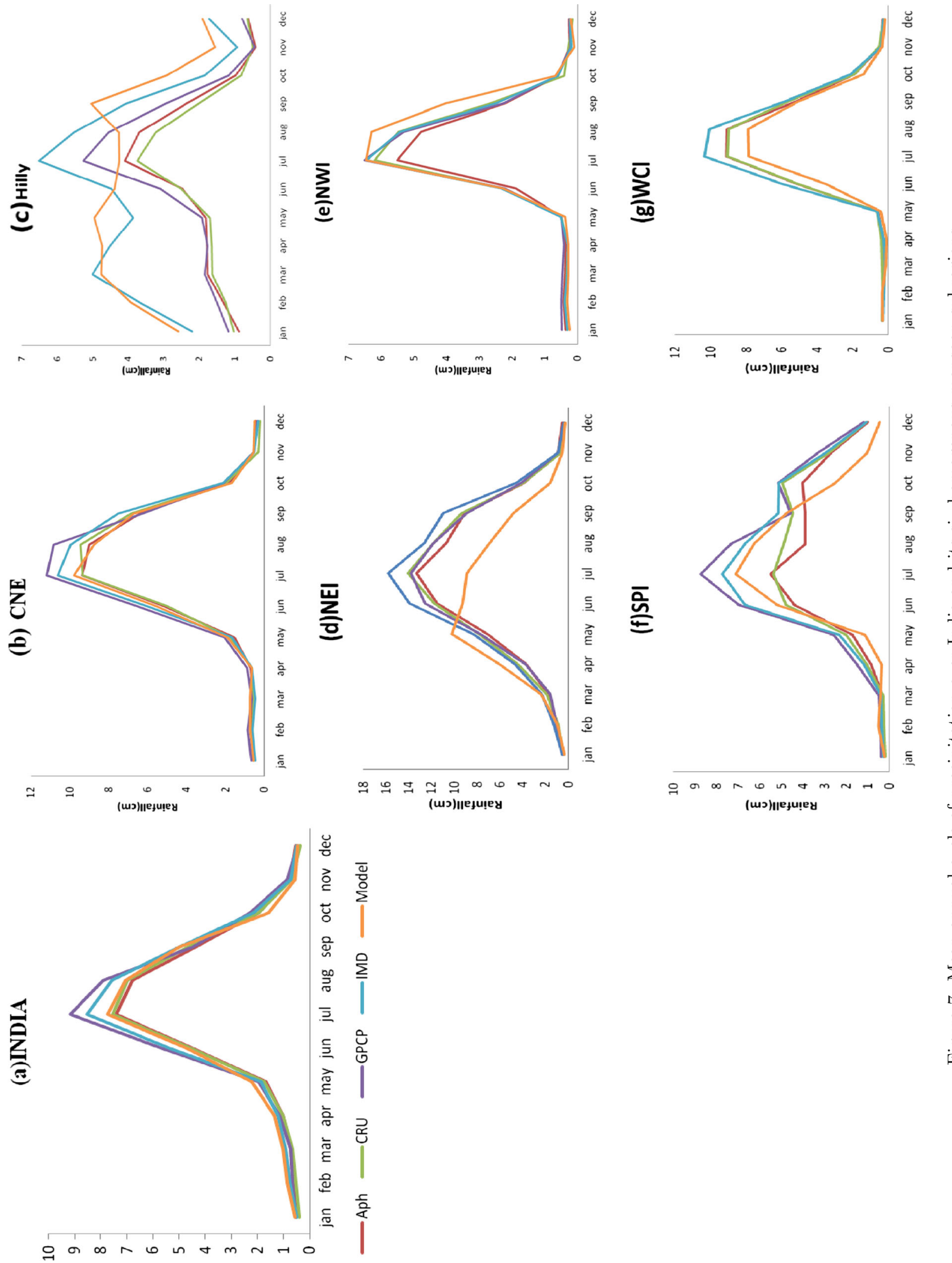

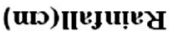


The values of COV and CC imply that the model captures the interannual variability as well as the magnitude over Hilly region. The interannual variability of the model shows close results with CRU and GPCP observational data set datasets compared to APH and IMD. The numbers of years that are in phase with the different observations over Hilly region are 13 for APH, 18 for CRU, 15 for GPCP and 12 for IMD (figure 8a). During the premonsoon period, the CCs over the Hilly region of the model with respect to APH, CRU, GPCP and IMD are $0.1,0.5,0.5,0.5$, and 0.6 , respectively. The respective $\mathrm{COV}$ values are $-16.3(\mathrm{APH}),-$ 21.0(CRU), -9.9 (GPCP) and -11.4(IMD), respectively. The interannual variability as well as the strength is captured over Hilly for CRU, GCPC and IMD data set (figure 8b). Though interannual variability is not captured well, the lower values of COV show that the strength is captured for APH.
The numbers of years that are in phase with the different observations over Hilly region are 11 for APH, 16 for CRU, 15 for GPCP and 15 for IMD. During ISM (June-September) the CCs varies from 0.1 (GPCP) to 0.3 (APH) for Indian region and the COV over the Indian region is found to be less in these observations and lies between -0.7 to $0.7 \%$ (table 2). So for ISM period the interannual variability is not captured but the magnitude of interannual variability is captured. The numbers of years in phase with the different observations are 10, 10, 11 and 10 for APH, GPCP, CRU and IMD, respectively for Indian region (figure 8c). Over CNE the CCs values vary and are 0.1 (IMD) to 0.3 (CRU) but the COV ranges from -4.8 (GPCP) to 3.2 (CRU) (table 2). The numbers of years that are in phase with the different observations over CNE region during ISM are 10 for $\mathrm{APH}, 14$ for CRU, 10 for GPCP and 6 for IMD (figure 8d). (a)

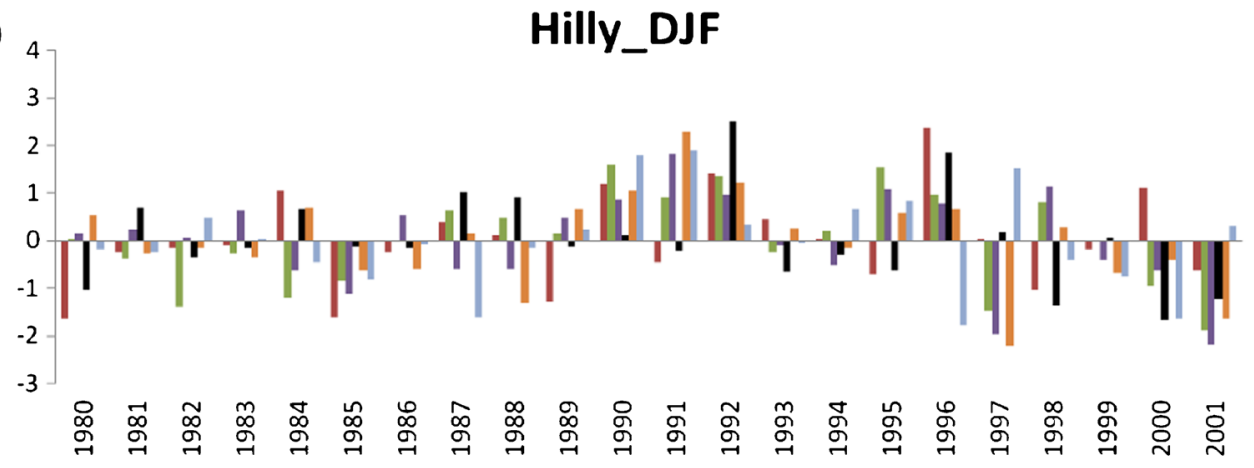

(b) 4

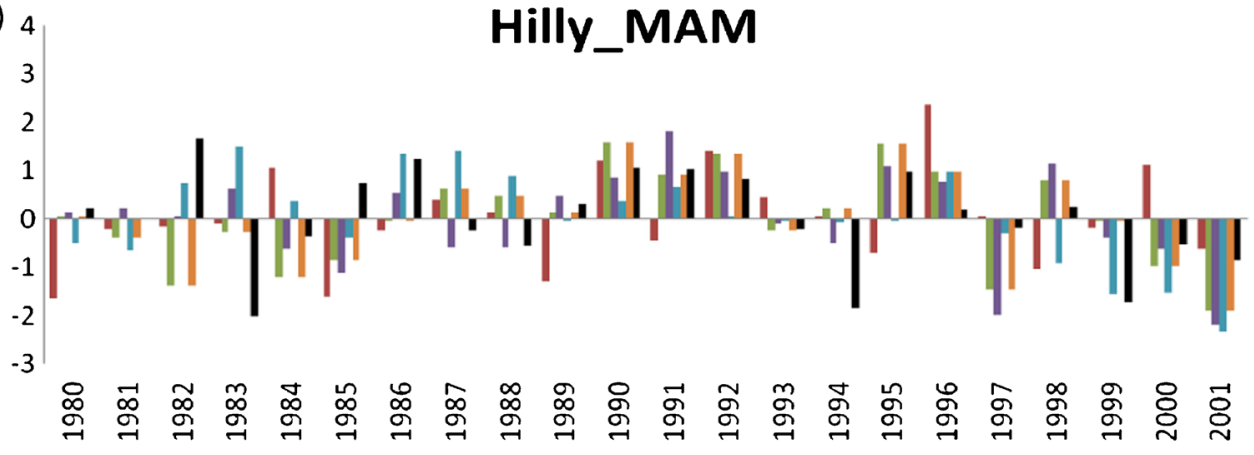

(c) 4

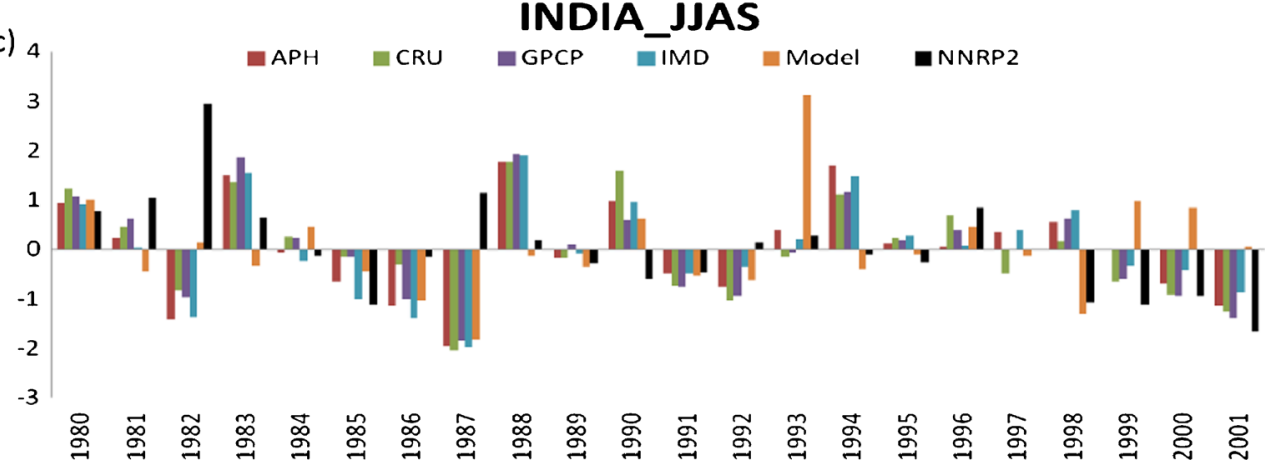

Figure 8. Normalized precipitation anomaly over (a) hilly region for winter season, (b) hilly region for pre-monsoon season, $(\mathbf{c}, \mathbf{d}$ and $\mathbf{e})$ over India, CNE and WCI for monsoon season respectively and (f) SPI for post-monsoon season. 
(d)

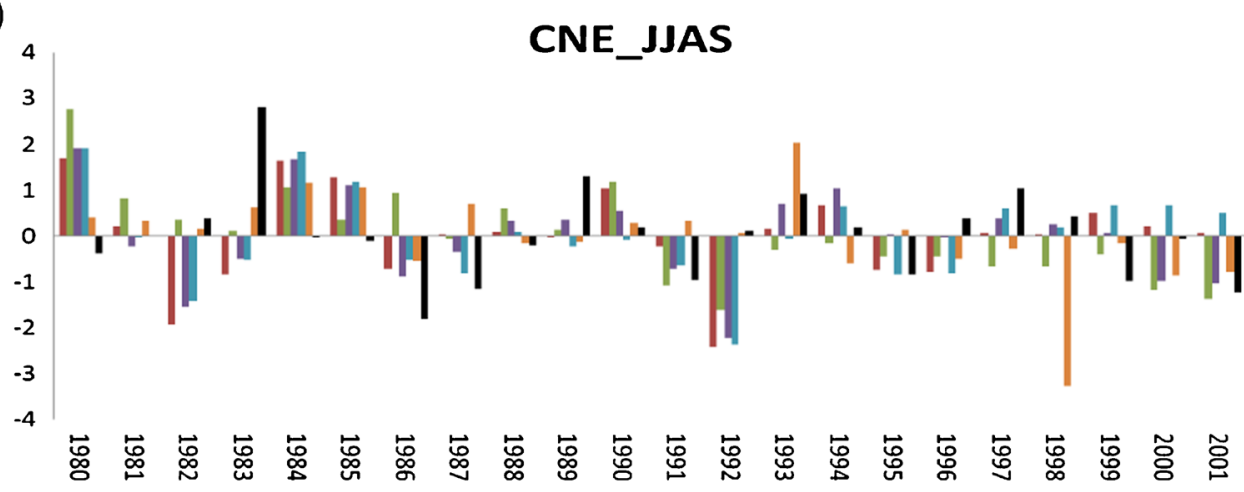

(e) 4
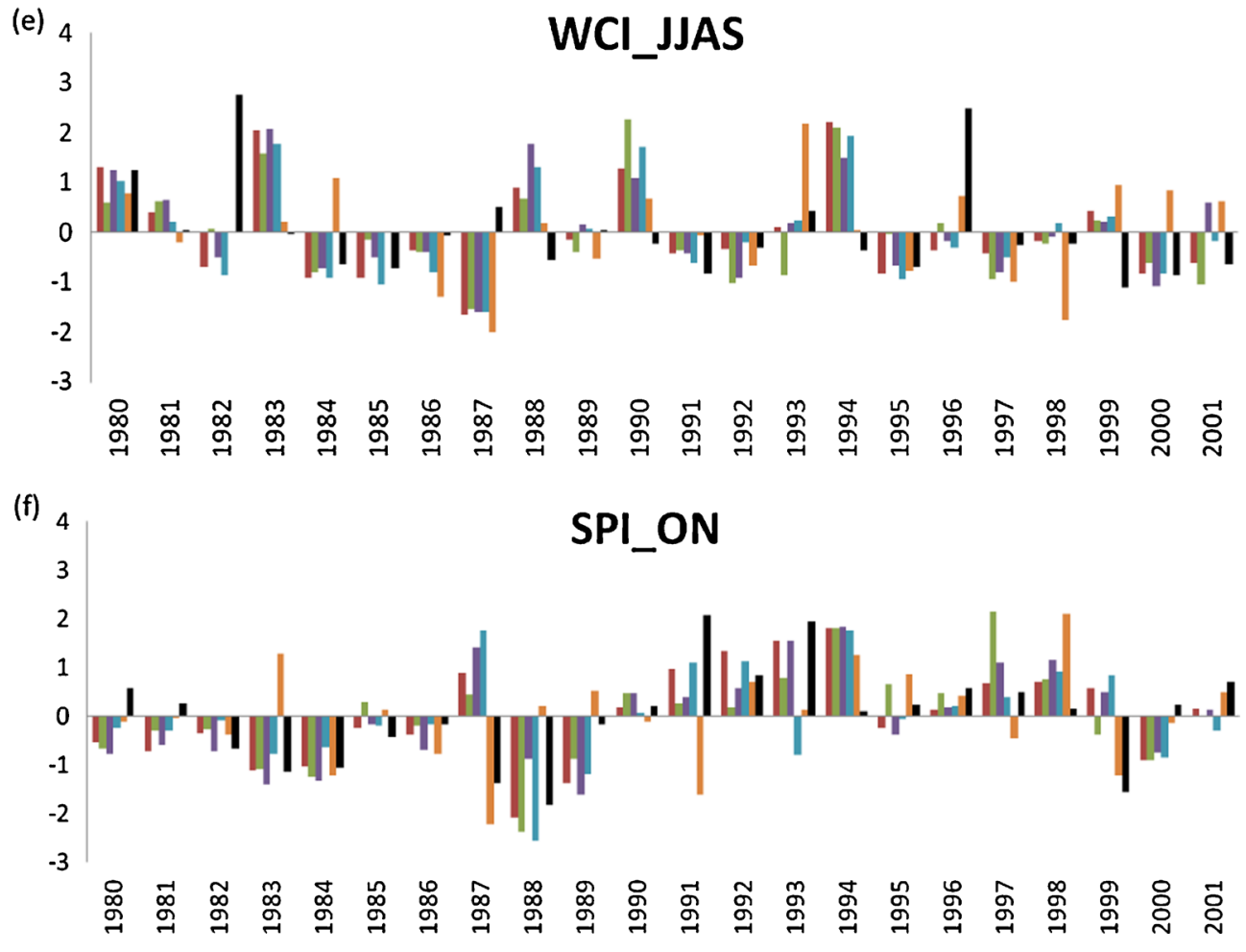

Figure 8. (Continued.)

For CNE subregion interannual variability and its strength are simulated better for CRU observation. The interannual variability of the WCI during the ISM is represented in the figure 8(e). The CCs over the WCI region of the model with respect to APH, CRU, GPCP and IMD are 0.3, 0.2, 0.4, and 0.3 , respectively. Similarly the respective COVs are 0.7 (APH), 0.1 (CRU), 1.8 (GPCP) and 1.9 (IMD). This shows that all observations except CRU are in good agreement to represent interannual variability and its strength over WCI. During OctoberNovember, the CCs for southern peninsular Indian region are very low and vary from -0.2 (IMD) to 0.1 (CRU). The COV also vary from -5.6 (IMD) to 2.6 (GPCP) (table 2). Since the NEM is not well captured by the model, the CCs are very low or negative, as reflected in the figure $8(\mathrm{f})$. The lower value of $\mathrm{COV}$ implies that the strength of the variability is captured. The $\mathrm{CC}$ and $\mathrm{COV}$ values for the rest of the subregions during the four seasons are represented in the table 2 .

The ability of the model to capture the extreme is compared using ETS measurement. ETS measures the fraction of observed and/or forecast events that were correctly simulated. The ETS measurement is a fairly good test for model verification for precipitation. The value of ETS ranges between -0.33 and 1 . The higher or positive value of ETS indicates that the model simulation is more capable of capturing the observed precipitation pattern. Whereas, ETS equal to 0 or negative value implies that there is no skill in the model simulation. The standardized anomaly precipitation values of the different seasons are taken for the calculation of the ETS for the present study. The standardised value of -1 or less is considered as the deficit precipitation year. Similarly, for the normal years the value lies within +1 to -1 and it is 
Table 2. Correlation coefficient (CC) between model and observed precipitation averaged over Indian and six homogenous subregions and the difference between coefficient of variations (COV).

\begin{tabular}{|c|c|c|c|c|c|c|c|c|}
\hline & \multicolumn{4}{|c|}{$\mathrm{CC}$} & \multicolumn{4}{|c|}{$\mathrm{COV}$} \\
\hline & $\overline{\mathrm{APH}}$ & $\mathrm{CRU}$ & GPCP & $\overline{\mathrm{IMD}}$ & $\overline{\mathrm{APH}}$ & $\mathrm{CRU}$ & GPCP & IMD \\
\hline \multicolumn{9}{|c|}{ December-January-February } \\
\hline India & -0.2 & 0.3 & 0.2 & 0.0 & -8.6 & -8.8 & 2.5 & 2.5 \\
\hline CNE & -0.1 & 0.4 & 0.4 & 0.1 & 13.7 & 24.7 & 7.6 & -6.0 \\
\hline Hilly & 0.2 & 0.6 & 0.8 & 0.2 & -10.2 & -14.9 & -3.8 & -15.8 \\
\hline NEI & 0.3 & 0.3 & 0.4 & 0.3 & 0.5 & 10.2 & 6.9 & -4.3 \\
\hline NWI & 0.4 & 0.4 & 0.3 & 0.4 & 20.9 & 16.2 & 16.9 & 10.3 \\
\hline SPI & 0.1 & 0.1 & 0.1 & -0.1 & 12.4 & 7.6 & -24.1 & -24.0 \\
\hline WCI & 0.4 & 0.2 & 0.4 & 0.3 & 19.2 & 14.9 & -5.8 & -32.5 \\
\hline \multicolumn{9}{|c|}{ March-April-May } \\
\hline India & 0.2 & 0.2 & 0.2 & 0.1 & 5.8 & 6.4 & 1.7 & 2.8 \\
\hline CNE & 0.6 & 0.4 & 0.6 & 0.6 & -47.8 & -12.2 & -41.3 & -33.2 \\
\hline Hilly & 0.1 & 0.5 & 0.5 & 0.6 & -16.3 & -21.0 & -9.9 & -11.4 \\
\hline NEI & 0.3 & 0.3 & 0.4 & 0.3 & 12.4 & 13.8 & 13.7 & 13.8 \\
\hline NWI & 0.4 & 0.4 & 0.3 & 0.4 & 37.1 & 35.1 & 26.3 & 13.2 \\
\hline SPI & 0.1 & 0.1 & 0.1 & -0.1 & 70.6 & 75.6 & 59.5 & 53.4 \\
\hline WCI & 0.4 & 0.2 & 0.4 & 0.3 & 35.2 & 46.2 & 25.8 & 24.8 \\
\hline \multicolumn{9}{|c|}{ June-July-August-September } \\
\hline India & 0.3 & 0.2 & 0.1 & 0.2 & 0.7 & 0.1 & -0.7 & 0.4 \\
\hline $\mathrm{CNE}$ & 0.2 & 0.3 & 0.2 & 0.1 & 2.8 & 3.2 & -4.8 & 2.3 \\
\hline Hilly & 0.3 & 0.1 & -0.1 & 0.2 & 0.6 & 5.9 & -0.1 & 4.3 \\
\hline NEI & 0.2 & 0.3 & 0.2 & 0.2 & 1.2 & 2.1 & 3.4 & 0.8 \\
\hline NWI & 0.6 & 0.5 & 0.5 & 0.5 & -9.7 & -8.5 & -8.6 & -9.9 \\
\hline SPI & -0.2 & 0.1 & -0.1 & 0.1 & -0.8 & 5.2 & 10.2 & 9.2 \\
\hline WCI & 0.3 & 0.2 & 0.4 & 0.3 & 0.7 & 0.1 & 1.8 & 1.9 \\
\hline \multicolumn{9}{|c|}{ October-November } \\
\hline India & 0.2 & 0.2 & 0.3 & 0.2 & -8.1 & -5.1 & -10.7 & -13.8 \\
\hline $\mathrm{CNE}$ & 0.1 & 0.1 & 0.3 & 0.1 & -13.1 & -6.9 & -16.9 & -26.9 \\
\hline Hilly & 0.1 & -0.1 & 0.2 & 0.1 & -11.8 & -33.0 & -21.5 & -19.4 \\
\hline NEI & 0.2 & 0.1 & 0.5 & 0.4 & 4.3 & 1.5 & 0.4 & -1.0 \\
\hline NWI & 0.0 & -0.1 & 0.0 & -0.1 & -18.0 & -36.8 & -51.2 & -66.2 \\
\hline SPI & -0.1 & 0.1 & 0.0 & -0.2 & -3.5 & 1.8 & 2.6 & -5.6 \\
\hline WCI & 0.4 & 0.3 & 0.3 & 0.3 & -6.6 & -7.3 & -4.8 & -13.0 \\
\hline
\end{tabular}

more than +1 for the excess precipitation years. Figure 9(a) represents the ETS score with different observed datasets over Hilly region during winter. The higher and positive values of the ETS imply that the deficit years are captured by the model with respect to the corresponding observational datasets (except APH and NNRP2 reanalysis). Similarly the model is nicely able to reproduce the excess year along the Hilly region during winter. The ETS score for Hilly region during the premonsoon season is shown in the figure 9(b). Similar to the winter time, the deficit years are captured by the model with respect to the corresponding observational datasets (except APH and NNRP2 reanalysis) but the excess years are also well represented with respect to APH, CRU and GPCP.
The model is able to capture the deficit years nicely for the Indian region during the summer time (figure 9c), but it fails to represent the excess years completely. Similarly, the model could not reproduce the deficit years over CNE during summer but the excess years are well captured (figure 9d). The model is able to represent the deficit years in the WCI region but fails to simulate the excess years (figure 9e). The model performs very well to captures both the deficit and excess years over the SPI during the post-monsoon season (figure $9 \mathrm{f}$ ).

Figure 10(a-f) shows the Taylor diagram of the model with respect to different observational datasets and NNRP2 reanalysis. Figure 10(a) depicts the Taylor diagram of Hilly region during the winter season. This shows that the GPCP 
and CRU data are very well correlated with the model with $\mathrm{CC}$ of 0.8 and 0.6 , respectively. The $\mathrm{APH}, \mathrm{IMD}$, and the NNRP2 reanalysis have low correlation coefficient around 0.2. The root mean square error (RMSE) is 0.6 for GPCP and 0.8 for CRU whereas for APH, IMD and NNRP2 reanalysis it is around 1.3. This shows that the model result is very close to the GPCP and CRU datasets during winter with least RMSE. Figure 10(b) represents the Taylor diagram of pre-monsoon over the hilly region; the CRU, GPCP, and IMD datasets show higher correlation with the model. The CCs are 0.5 (CRU), 0.5 (GPCP), and 0.6 (IMD). The $\mathrm{CC}$ of APH and NNRP2 reanalysis lies between 0.02 and 0.2 . The RMSE for the CRU, IMD, and GPCP datasets varies from 0.9 to 1.05. The APH and NNRP2 have higher RMSE of 1.4 and 1.3, respectively. The Taylor diagram of India during ISM (figure 10c) shows that all the observations and the NNRP2 reanalysis shows CCs ranging from 0.2 and 0.3 over India. The RMSE also ranges between 1.2 and 1.3 for all observational datasets. The Taylor diagram of CNE over ISM is presented in figure $10(\mathrm{~d})$. The CCs range from 0.1 to 0.3 and also the RMSEs are on higher side ranging from 1.2 to 1.4 . The Taylor diagram for WCI shows that the $\mathrm{CC}$ varies from 0.2 to 0.4 for different observational analysis (figure 10e). The RMSE for different observational analysis varies from 1.05 to 1.35 . Figure $10(f)$ explains the Taylor diagram of the southern India during post-monsoon. The NEM is not captured so the model is not very well correlated with the observational dataset and the NNRP2 reanalysis, and ranges from -0.2 to 0.2 . The RMSE also ranges from 1.3 to 1.5 for all the observational datasets and NNRP2 reanalysis. The above analysis (figure 8) reflects that the model interannual variability in terms of standardized anomaly is not in agreement with the NNRP2 reanalysis over India and different subregions for different seasons. The model also fails to capture the excess, normal, and (a)

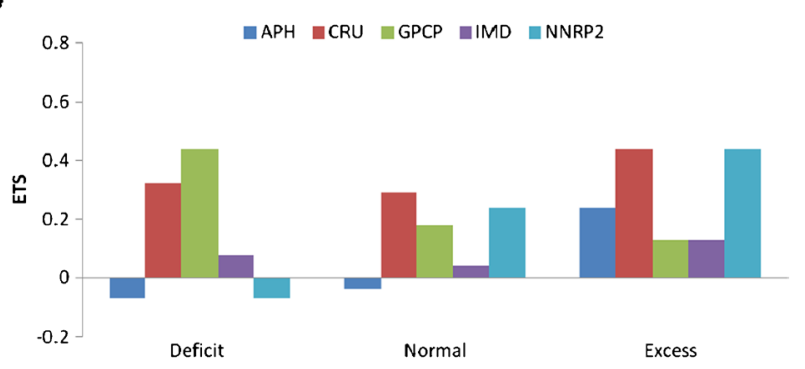

(c)

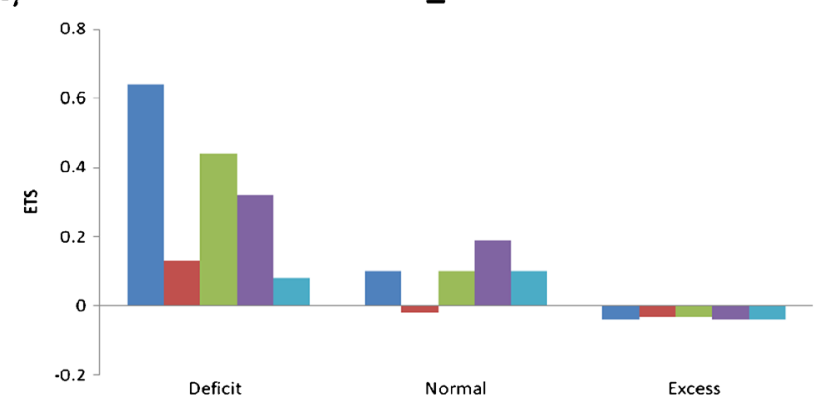

(e)

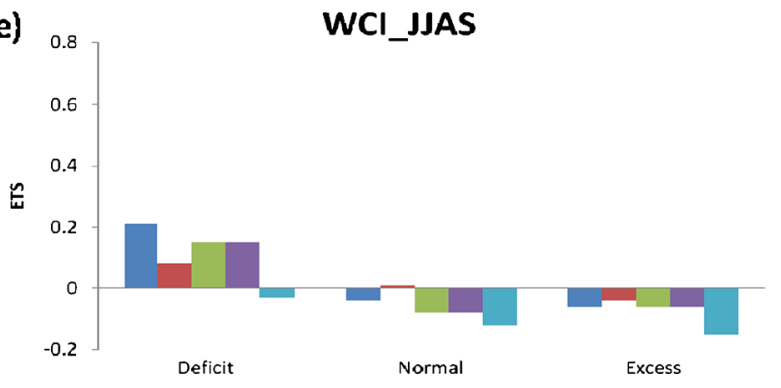

INDIA_JJAS
Hilly_DJF

(d)
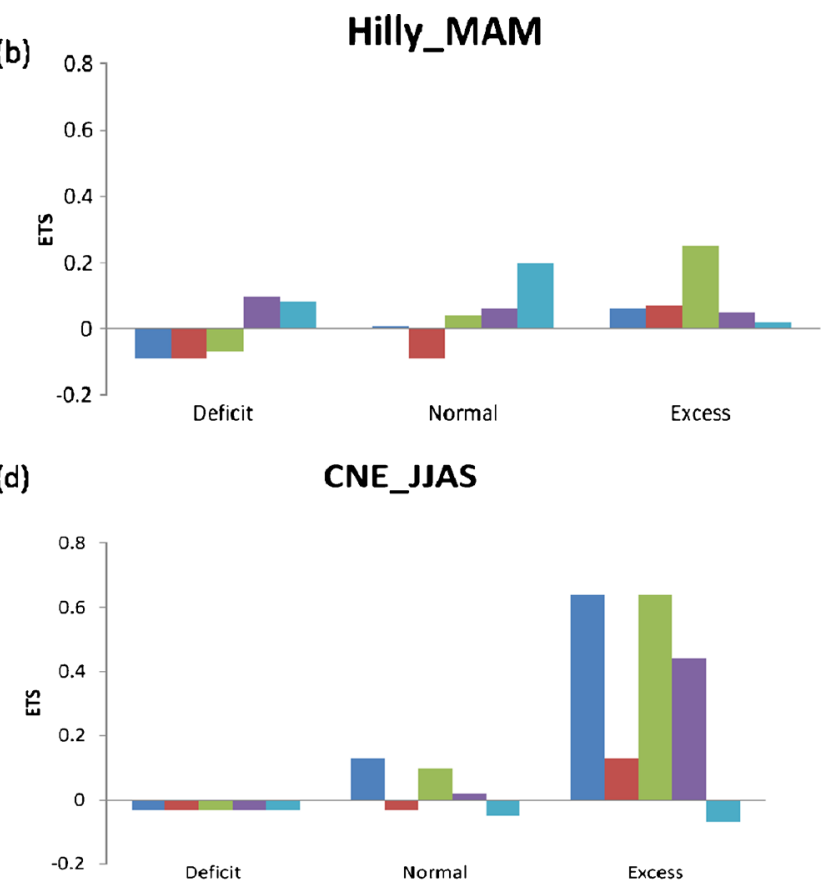

(f)

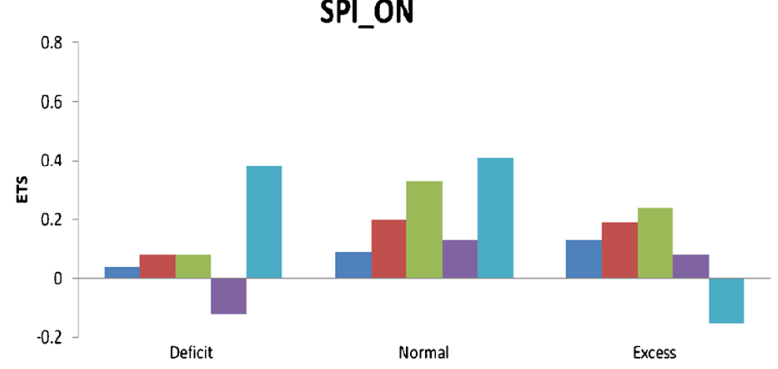

Figure 9. The Equitable Threat Score (ETS) of the model with respect to different observational datasets and the NNRP2 reanalysis for (a) Hilly_DJF, (b) Hilly_MAM, (c) INDIA_JJAS, (d) CNE_JJAS, (e) WCI_JJAS and (f) SPI_ON. 
(a) Hilly_DJF

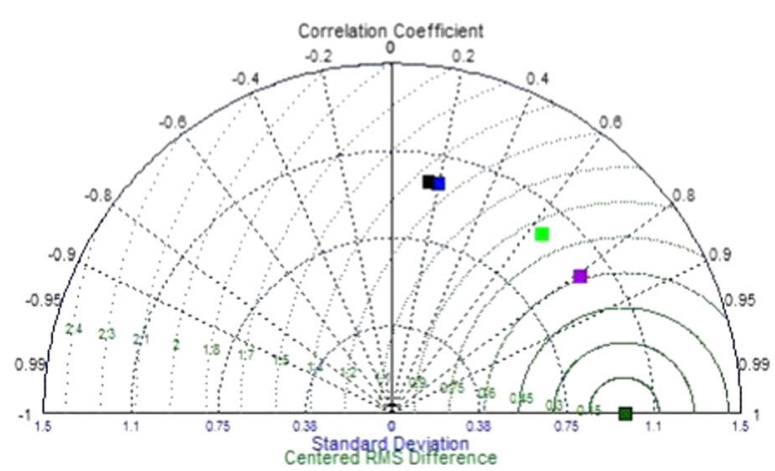

(c) India_JJAS

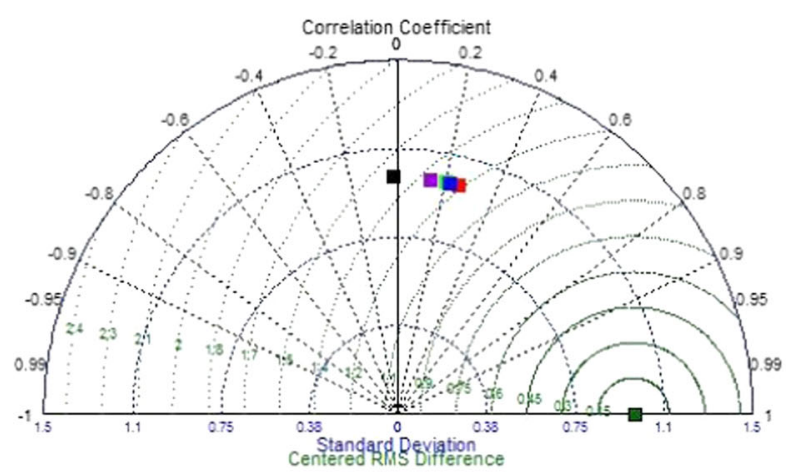

(e) WCI_JJAS

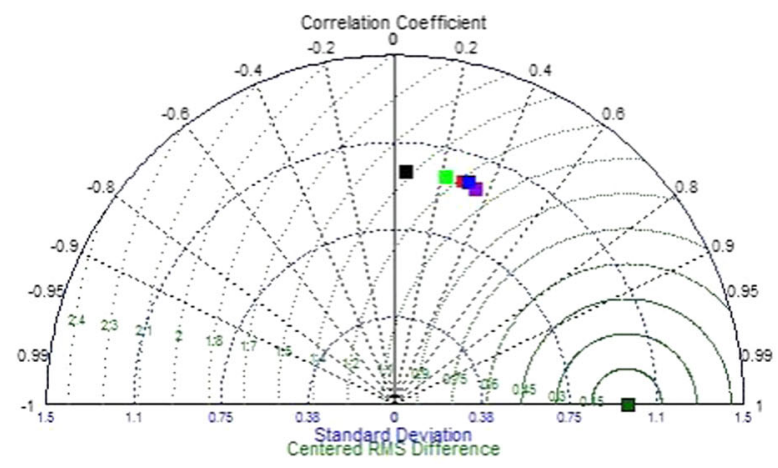

(b) Hilly_MAM

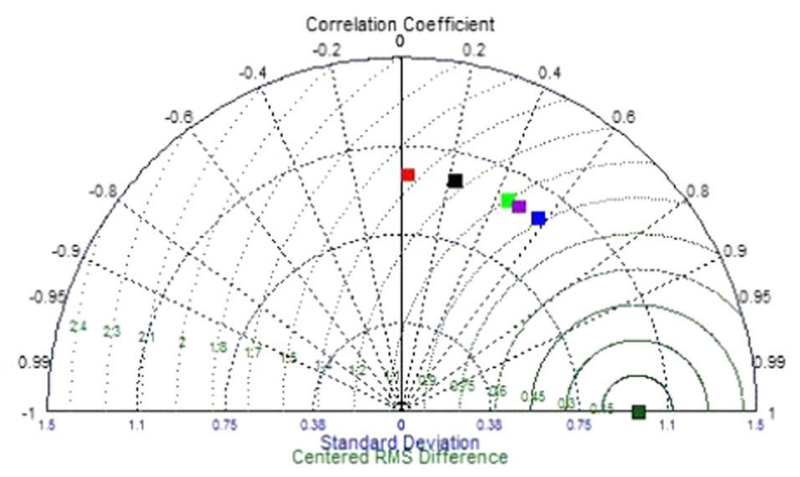

(d) CNE_JJAS

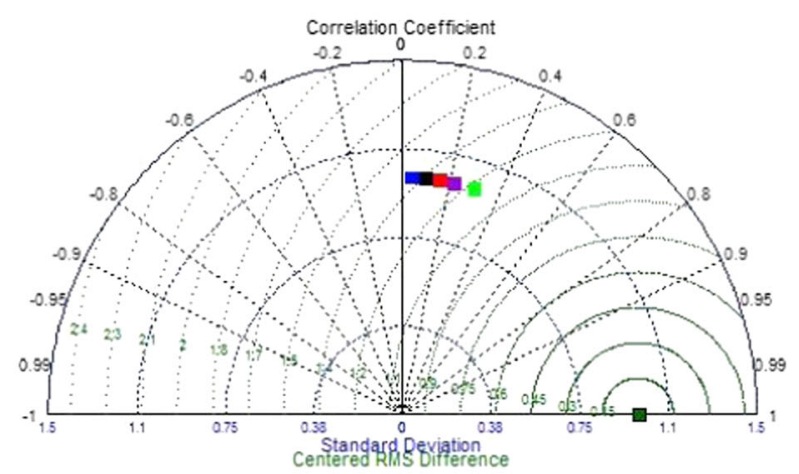

(f) SPI_ON

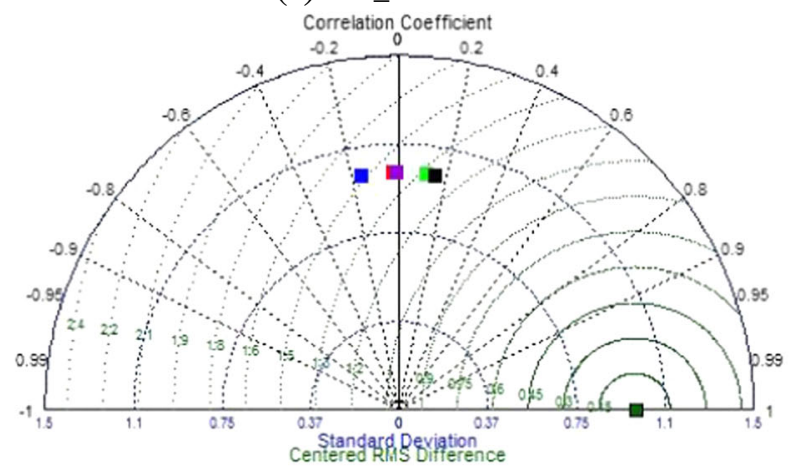

IMD

NNRP2

model

Figure 10. Taylor diagram of the model with respect to different observational datasets and the NNRP2 reanalysis for (a) Hilly_DJF, (b) Hilly_MAM, (c) INDIA_JJAS, (d) CNE_JJAS, (e) WCI_JJAS and (f) SPI_ON.

deficit years with respect to NNRP2 reanalysis. Moreover, figure 10 shows that the NNRP2 reanalysis is also not well correlated with the model and shows higher RMSE. From this it can be concluded that the model processes are more dominant in deciding the interannual variability than the ICBC. If the ICBC had played a major role in deciding the interannual variability, then the interannual variability would have matched with the corresponding reanalysis in most of the cases.

\subsection{Contribution of seasonal precipitation over six homogeneous subregions to seasonal precipitation over Indian region}

Over the hilly region of Jammu \& Kashmir, major precipitation is contributed by winter (DecemberFebruary) WDs in percentage and quantity (table 3). But the major fraction of the total precipitation comes from the SPI as observed in different observational datasets. The model 
Table 3. Contribution of seasonal precipitation over six homogenous subregions to seasonal precipitation over Indian region.

\begin{tabular}{|c|c|c|c|c|c|c|c|c|}
\hline & & India & $\mathrm{CNE}$ & Hilly & NEI & NWI & SPI & WCI \\
\hline \multicolumn{9}{|c|}{ December-January-February } \\
\hline \multirow[t]{2}{*}{ RegCM3 } & $\%$ contribution & 100 & 13.3 & 44.5 & 5.8 & 14.9 & 14.7 & 7.6 \\
\hline & volume $\left(\mathrm{m}^{3} * 10^{10}\right)$ & 23.3 & 3.1 & 10.4 & 1.4 & 3.5 & 3.4 & 1.8 \\
\hline \multirow[t]{2}{*}{$\mathrm{APH}$} & $\%$ contribution & 100 & 14.4 & 15.9 & 7.2 & 10.3 & 42.9 & 9.9 \\
\hline & volume $\left(\mathrm{m}^{3} * 10^{10}\right)$ & 18.0 & 2.6 & 2.9 & 1.3 & 1.8 & 7.7 & 1.8 \\
\hline \multirow[t]{2}{*}{$\mathrm{CRU}$} & $\%$ contribution & 100 & 15.5 & 18.0 & 9.30 & 9.4 & 40.4 & 7.8 \\
\hline & volume $\left(\mathrm{m}^{3} * 10^{10}\right)$ & 18.0 & 2.8 & 3.2 & 1.7 & 1.7 & 7.3 & 1.4 \\
\hline \multirow[t]{2}{*}{ GPCP } & $\%$ contribution & 100 & 14.9 & 19.0 & 8.9 & 10.5 & 38.5 & 8.8 \\
\hline & volume $\left(\mathrm{m}^{3} * 10^{10}\right)$ & 16.1 & 2.4 & 3.0 & 1.4 & 1.7 & 6.2 & 1.4 \\
\hline \multirow[t]{2}{*}{ IMD } & $\%$ contribution & 100 & 12.99 & 33.83 & 7.53 & 9.52 & 28.31 & 8.22 \\
\hline & volume $\left(\mathrm{m}^{3} * 10^{10}\right)$ & 17.1 & 2.2 & 5.8 & 1.3 & 1.6 & 4.8 & 1.4 \\
\hline \multicolumn{9}{|c|}{ March-April-May } \\
\hline \multirow[t]{2}{*}{ RegCM3 } & $\%$ contribution & 100 & 12.0 & 35.1 & 31.8 & 5.8 & 11.9 & 3.3 \\
\hline & volume $\left(\mathrm{m}^{3} * 10^{10}\right)$ & 49.2 & 5.9 & 17.3 & 15.6 & 2.9 & 5.9 & 1.6 \\
\hline \multirow[t]{2}{*}{$\mathrm{APH}$} & $\%$ contribution & 100 & 13.8 & 15.8 & 30.1 & 7.9 & 28.2 & 4.8 \\
\hline & volume $\left(\mathrm{m}^{3} * 10^{10}\right)$ & 35.5 & 4.9 & 5.6 & 10.7 & 2.8 & 10.0 & 1.7 \\
\hline \multirow[t]{2}{*}{$\mathrm{CRU}$} & $\%$ contribution & 100 & 13.9 & 15.9 & 30.8 & 5.8 & 29.2 & 5.2 \\
\hline & volume $\left(\mathrm{m}^{3} * 10^{10}\right)$ & 39.7 & 5.5 & 6.3 & 12.2 & 2.3 & 11.6 & 2.0 \\
\hline \multirow[t]{2}{*}{ GPCP } & $\%$ contribution & 100 & 14.0 & 15.9 & 28.3 & 6.8 & 29.8 & 5.1 \\
\hline & volume $\left(\mathrm{m}^{3} * 10^{10}\right)$ & 39.3 & 5.5 & 6.3 & 11.1 & 2.7 & 11.7 & 2.0 \\
\hline \multirow[t]{2}{*}{ IMD } & $\%$ contribution & 100 & 12.0 & 23.8 & 28.1 & 5.3 & 27.3 & 3.9 \\
\hline & volume $\left(\mathrm{m}^{3} * 10^{10}\right)$ & 40.5 & 4.8 & 9.6 & 11.3 & 2.1 & 11.0 & 1.5 \\
\hline \multicolumn{9}{|c|}{ June--July-August-September } \\
\hline \multirow[t]{2}{*}{ RegCM3 } & $\%$ contribution & 100 & 22.0 & 9.4 & 10.2 & 15.6 & 27.7 & 15.0 \\
\hline & volume $\left(\mathrm{m}^{3} * 10^{12}\right)$ & 24.5 & 5.4 & 2.3 & 2.5 & 3.8 & 6.8 & 3.7 \\
\hline \multirow[t]{2}{*}{$\mathrm{APH}$} & $\%$ contribution & 100 & 22.5 & 6.9 & 16.2 & 12.1 & 25.5 & 16.8 \\
\hline & volume $\left(\mathrm{m}^{3} * 10^{12}\right)$ & 23.2 & 5.2 & 1.6 & 3.8 & 2.8 & 5.9 & 3.9 \\
\hline \multirow[t]{2}{*}{$\mathrm{CRU}$} & $\%$ contribution & 100 & 22.2 & 7.0 & 16.3 & 13.2 & 25.2 & 16.2 \\
\hline & volume $\left(\mathrm{m}^{3} * 10^{12}\right)$ & 24.4 & 5.4 & 1.7 & 4.0 & 3.2 & 6.2 & 3.9 \\
\hline \multirow[t]{2}{*}{ GPCP } & $\%$ contribution & 100 & 22.2 & 7.1 & 14.4 & 11.7 & 28.8 & 15.8 \\
\hline & volume $\left(\mathrm{m}^{3} * 10^{12}\right)$ & 28.1 & 6.2 & 2.0 & 4.0 & 3.3 & 8.1 & 4.4 \\
\hline \multirow[t]{2}{*}{ IMD } & $\%$ contribution & 100 & 21.9 & 9.1 & 16.1 & 11.9 & 26.6 & 15.0 \\
\hline & volume $\left(\mathrm{m}^{3} * 10^{12}\right)$ & 26.6 & 5.8 & 2.4 & 4.3 & 3.2 & 7.1 & 4.0 \\
\hline \multicolumn{9}{|c|}{ October-November } \\
\hline \multirow[t]{2}{*}{ RegCM3 } & $\%$ contribution & 100 & 13.9 & 22.3 & 7.2 & 14.4 & 32.6 & 9.9 \\
\hline & volume $\left(\mathrm{m}^{3} * 10^{10}\right)$ & 25.2 & 3.5 & 5.6 & 1.8 & 3.6 & 8.2 & 2.5 \\
\hline \multirow[t]{2}{*}{$\mathrm{APH}$} & $\%$ contribution & 100 & 13.1 & 6.7 & 14.0 & 7.6 & 47.3 & 11.5 \\
\hline & volume $\left(\mathrm{m}^{3} * 10^{10}\right)$ & 26.9 & 3.5 & 1.8 & 3.8 & 2.0 & 12.7 & 3.1 \\
\hline \multirow[t]{2}{*}{$\mathrm{CRU}$} & $\%$ contribution & 100 & 13.3 & 5.5 & 12.9 & 4.6 & 52.7 & 11.4 \\
\hline & volume $\left(\mathrm{m}^{3} * 10^{10}\right)$ & 30.4 & 4.1 & 1.7 & 3.9 & 1.4 & 16.0 & 3.5 \\
\hline GPCP & $\%$ contribution & 100 & 12.3 & 6.1 & 11.6 & 5.8 & 54.4 & 10.4 \\
\hline & volume $\left(\mathrm{m}^{3} * 10^{10}\right)$ & 35.0 & 4.3 & 2.1 & 4.0 & 2.0 & 19.1 & 3.6 \\
\hline IMD & $\%$ contribution & 100 & 14.3 & 9.2 & 14.1 & 4.8 & 47.3 & 10.9 \\
\hline & volume $\left(\mathrm{m}^{3} * 10^{10}\right)$ & 27.9 & 4.0 & 2.5 & 3.9 & 1.3 & 13.2 & 3.1 \\
\hline
\end{tabular}

simulates its maximum precipitation over the hilly and NWI subregions, which contributes around $45 \%$ and $15 \%$ of the total precipitation, respectively, over the Indian region. The model overestimates precipitation over these subregions. The precipitation contributions from CNE and WCI subregions are well captured by the model, whereas the model underestimates precipitation over NEI and SPI subregions.

During the pre-monsoon period (March-May), major contribution of precipitation comes from hilly, NEI and SPI subregions (table 3). The model is able to capture the precipitation well for CNE,
NEI, NWI and WCI subregions. The model shows higher contribution of precipitation from the hilly subregion $(35.1 \%)$ and underestimates the contribution from the SPI subregion (12.0\%). The contribution from hilly subregion for APH is $15.8 \%$ and for IMD it is $23.8 \%$. In the case of SPI subregion contribution for IMD, observation is $27.3 \%$ and for GPCP is $29.8 \%$. In terms of quantity, the major contribution during pre-monsoon period is from NEI and SPI subregions, whereas in model NEI and hilly subregions show major contribution towards Indian region. In case of contribution from the rest of the subregions, the model could 
simulate percentage contribution with reasonable limits.

During ISM (June-September), the contribution of precipitation in percentage as well as quantity is well captured by the model over CNE, SPI, and WCI subregions. The model shows overestimation in percentage precipitation contribution from the hilly and NWI subregions and underestimates from the NEI subregion. The major precipitation contributing areas are CNE (21.9-22.5\%) and SPI (25.5-28.8\%), which are captured well by the model. In terms of quantity also, these two subregions contribute maximum to the ISM.

During the post-monsoon period (OctoberNovember), a major percentage of precipitation comes from CNE, NEI and SPI subregions. In model simulations, major contribution of precipitation is shown from the hilly, NWI, and SPI subregions. It overestimates over the hilly and NWI subregions and underestimates over NEI and SPI subregions. In terms of quantitative contribution CNE, NEI and SPI subregions are the main contributors during post-monsoon period. In model simulations, CNE, hilly and SPI subregions are the main contributors and NEI subregion is the least contributor in post-monsoon precipitation over the Indian region.

3.5 Contribution of annual precipitation over six homogeneous subregions to annual precipitation over Indian region

The quantity and percentage contribution of annual precipitation by each subregion to the annual precipitation over the Indian region are shown in table 4 . The model is showing good agreement in percentage of annual precipitation from CNE, NEI, NWI, and WCI subregions contribution to annual precipitation over Indian region. In model simulations, hilly subregion is the main contributor area for model precipitation, and WCI is the least contributing. From the corresponding observations, the major contributing subregion to the total precipitation in percentage is SPI. In terms of quantity the major contributing subregions are CNE and SPI in observations, whereas in model simulations hilly and NWI are the major contributors. The model overestimates precipitation when compared to the corresponding observation over these two major contributing regions. The model shows good agreement over the CNE and over remaining subregions, the model underestimates precipitation.

\subsection{Contribution of seasonal precipitation over Indian region to annual precipitation over Indian region}

The contribution from each season to the total annual average precipitation over the Indian region is computed and compared in model simulations and the corresponding observations are shown in table 5. In model simulation, winter season contributes about $7 \%$ of the total precipitation. Comparison with different observations shows that winter contributes about $5.8 \%$ for $\mathrm{APH}$ to $4.9 \%$ for IMD precipitation to the total precipitation. Similarly pre-monsoon season contributes about $14.8 \%$ to the total precipitation in the simulation which is higher when compared to the corresponding observations which is between $10.6 \%$ for GPCP and $12.1 \%$ for CRU. During summer monsoon season, contribution of $72.7 \%$ of the total rain over Indian region is seen in the model environment, which is also closely seen in the corresponding observations which varies between $73.6 \%$ for CRU and $76.1 \%$ for IMD. In post-monsoon season, the model is able to capture the percentage of precipitation $(7.4 \%)$ which is close to the corresponding observations where values lie between $7.9 \%$ for IMD and $9.2 \%$ for GPCP. The model is able to capture the seasonal contribution of precipitation quite well over India.

Table 4. Contribution of annual precipitation over six homogeneous subregions to annual precipitation over Indian region.

\begin{tabular}{|c|c|c|c|c|c|c|c|c|}
\hline & & India & $\mathrm{CNE}$ & Hilly & NEI & NWI & SPI & WCI \\
\hline \multirow[t]{2}{*}{ RegCM3 } & \multirow{2}{*}{$\begin{array}{l}\% \text { contribution } \\
\text { volume }\left(\mathrm{m}^{3} * 10^{11}\right)\end{array}$} & 100 & 19.9 & 17.1 & 13.1 & 12.5 & 26.4 & 11.4 \\
\hline & & 33.1 & 6.6 & 5.7 & 4.3 & 4.1 & 8.7 & 3.8 \\
\hline \multirow[t]{2}{*}{$\mathrm{APH}$} & \multirow{2}{*}{$\begin{array}{l}\% \text { contribution } \\
\text { volume }\left(\mathrm{m}^{3} * 10^{11}\right)\end{array}$} & 100 & 19.6 & 8.3 & 16.8 & 10.5 & 31.2 & 13.9 \\
\hline & & 30.9 & 6.0 & 2.6 & 5.2 & 3.2 & 9.6 & 4.2 \\
\hline \multirow[t]{2}{*}{ CRU } & \multirow{2}{*}{$\begin{array}{l}\% \text { contribution } \\
\text { volume }\left(\mathrm{m}^{3} * 10^{11}\right)\end{array}$} & 100 & 20.0 & 8.2 & 14.6 & 11.3 & 31.7 & 14.0 \\
\hline & & 32.9 & 6.6 & 2.7 & 4.8 & 3.7 & 10.4 & 4.6 \\
\hline \multirow[t]{2}{*}{ GPCP } & \multirow{2}{*}{$\begin{array}{l}\% \text { contribution } \\
\text { volume }\left(\mathrm{m}^{3} * 10^{11}\right)\end{array}$} & 100 & 19.8 & 8.7 & 16.0 & 10.5 & 31.9 & 13.8 \\
\hline & & 37.3 & 7.4 & 3.2 & 5.9 & 3.9 & 11.9 & 5.1 \\
\hline \multirow[t]{2}{*}{ IMD } & $\%$ contribution & 100 & 20.1 & 9.2 & 16.0 & 10.6 & 31.2 & 13.2 \\
\hline & volume $\left(\mathrm{m}^{3} * 10^{11}\right)$ & 35.0 & 7.0 & 3.2 & 5.6 & 3.7 & 10.9 & 4.6 \\
\hline
\end{tabular}


Table 5. Contribution of seasonal precipitation over Indian region to annual precipitation over Indian region in percentage.

\begin{tabular}{lccccc}
\hline & DJF & MAM & JJAS & ON & Annual \\
\hline RegCM3 & 7.0 & 13.3 & 72.5 & 7.2 & 100.0 \\
APH & 5.8 & 11.5 & 74.4 & 8.3 & 100.0 \\
CRU & 5.5 & 11.9 & 735 & 9.1 & 100.0 \\
GPCP & 4.6 & 10.7 & 75.5 & 9.2 & 100.0 \\
IMD & 4.8 & 11.6 & 75.8 & 7.8 & 100.0 \\
\hline
\end{tabular}

\section{Summary and conclusions}

In this study, the RegCM3 model is used for the regional climatic simulation over the larger domain comprising Indian subcontinent. Because of the larger domain, the model has its freedom to reproduce its own circulation, temperature, and precipitation fields. The main seasonal features of the wind, such as the southward movement of the STWJ below the Himalayas during winter, the TEJ, STWJ, the position of Tibetan anticyclone over India, and the Findlater jet over the Arabian Sea along with the wind reversal at the lower and upper levels during monsoon and the north-easterly during the post-monsoon period are well represented in the simulation. The model is able to reproduce the seasonal spatial distribution of the precipitation along with the peaks for all seasons, such as Jammu and Kashmir region receives rainfall during the winter, hilly region during pre-monsoon, Western Ghats and northeast region during monsoon and southern India during post-monsoon season. The spatial distribution of the model simulated temperature is showing good agreement with the observations over India for all the seasons. During monsoon, the interaction of the moisture laden southwesterly with the Western Ghats cause heavy precipitation by shedding most of its moisture over this region. The warmer Bay of Bengal removes the moisture in the atmosphere around the seas. Both the phenomena together cause decrease of moisture in the model environment. This results in less precipitation over the monsoon core region, which shows dry bias. The excess rain in the Indian landmass during monsoon cause the surface wetness and the evaporation of the water cools down the surface. So the whole India shows cold bias during the ISM. The reduced moisture availability and low pressure gradient between land and sea causes weak northeast monsoon during post-monsoon season in the simulation. The model nicely captures the temporal variation or the mean annual cycle of precipitation over India, CNE, NWI, NWI and WCI. The phase of the monsoon and the amplitude is simulated with a lesser bias over India.
The precipitation over the hilly region during the monsoon and winter is well represented in the simulation. The onset, evolution, and offset of the monsoon are well captured by the model. The model representation of the seasonal contribution of the precipitation to the total Indian precipitation is in agreement with the corresponding observations, where DJF, MAM, JJAS and ON contribute around $7,13.5,72.5$ and $7.3 \%$, respectively. The subregional contribution of the precipitation to the total precipitation over India is well captured by the model over CNE, NEI, NWI and WCI. The model overestimates the contribution by the hilly region because this region gets rainfall due to both, strong westerly winds during winter and southwesterly winds during monsoon, whereas it underestimates the precipitation over the SPI due to weak northeast monsoon.

During winter, the model captures the interannual variability with very lesser RMSE over hilly region, which is the most relevant region during this season. The model shows good skills in capturing the normal, deficit, and excess years over this region. The major contribution of precipitation comes from hilly region to the total winter precipitation in the simulation. The hilly region receives heavy precipitation due to the strong westerly winds as a result of which it overestimates the rainfall over this region. Besides that, the model reproduces well the winter time precipitation contribution of CNE and WCI. During the pre-monsoon period, the interannual variability is nicely captured over the hilly region. The model shows the ability to capture the excess years but the deficit years are not well captured over hilly region. The RMSE over this region is less for most of the observational datasets with respect to model simulation. The NEI and hilly regions are the major contributors to the pre-monsoonal precipitation in the model because these regions get rainfall due to pre-monsoon thunderstorms and hence overestimate rainfall compared to the corresponding observations. The model nicely captures the percentage contribution of precipitation over the CNE, NEI, NWI, and WCI. During summer, the interannual variability of rainfall is not well captured over India although the RMSE is less. The model shows good skills to capture the deficit years and normal years but the excess years are not captured. The interannual variability is not well represented over CNE and WCI subregions during ISM but the RMSE values are less. The model shows very good skill in capturing the normal and excess years over CNE but fails to simulate the deficit years. Whereas the deficit years are well represented over the WCI but the normal and excess years are not well captured. The major precipitation contributing subregions CNE and SPI, and also the precipitation 
contribution in percentage over CNE, SPI, and WCI subregions to the total summer monsoonal precipitation is well represented in the simulation. During the post-monsoon period, the interannual variability is not captured well with high RMSE over SPI. But the model shows good skill in simulating the deficit, normal, and excess years in most of the years. The precipitation contribution in percentage is well captured over CNE and WCI subregions to the total post-monsoonal precipitation. The model contribution of the SPI to total postmonsoonal precipitation is less due to the weak northeast monsoon in the model. The model fails to capture the seasonal interannual variability with respect to the NNRP2 reanalysis over India and most of its subregions. The extreme years are not in agreement and also the RMSE is high for NNRP2 reanalysis. The large domain with complex terrain of simulation provides the model to reproduce its own local processes, which may not able to reproduce very fine scale local processes. This shows that the model processes are more important than the initial and boundary conditions during determination of variability as found in case of the Sylla (2009a) over African domain.

The conclusions of the study are:

- The model shows good skill in reproducing the climatology and mean annual cycle over the Indian landmass and its subregions.

- In most of the years, the interannual variability of the precipitation is not captured, because model processes are found to be more important than the initial and boundary conditions during determination of variability.

- The seasonal contribution of the precipitation to the total Indian precipitation is well represented by the model.

- The subregional contribution to the total precipitation is well captured for CNE, NEI, NWI, and WCI.

- The overall performance of the model is good in relevant subregions for each of the four seasons in reproducing the variability and the extreme years, but the model shows improved performance over WCI and NWI subregions.

In future study, the focus will be on the intraseasonal variability and daily rainfall analysis over India and its subregions.

\section{Acknowledgements}

The first author thanks the Council of Scientific and Industrial Research (CSIR) for the financial help during the study. The author is also thankful to Mr K C Pattnayak and Mr S Panda (IIT, Delhi) for their valuable help and guidance. The authors also thank the anonymous reviewers for their valuable suggestions during the preparation of the manuscript.

\section{References}

Adler R F, Huffman G J, Chang A, Ferraro R, Xie P, Janowiak J et al. 2003 The Version 2 Global Precipitation Climatology Project (GPCP) monthly precipitation analysis (1979-Present); J. Hydrometeor. 4 11471167.

Afiesimama E A, Pal J S, Abiodun B J, Gutiwski W J and Adedoyin A 2006 Simulation of west African monsoon using the RegCM3. Part I: Model validation and interannual variability; Theor. Appl. Climatol. 86 23-37.

Cadet D 1979 Meteorology of Indian summer monsoon; Nature 279 761-767.

Dash S K, Shekhar M S, Singh G P and Vernekar A D 2002 Relationship between surface fields over Indian Ocean and monsoon precipitation over homogeneous zones of India; Mausam 53 133-144.

Dash S K, Singh G P, Shekar M S and Vernekar A D 2005 Response of the Indian summer monsoon circulation and rainfall to seasonal snow depth anomaly over Eurasia; Clim. Dyn. 24 1-10.

Dash S K, Shekhar M S and Singh G P 2006 Simulation of Indian summer monsoon circulation and precipitation using RegCM3; Theor. Appl. Climatol. 86 161-172, doi: 10.1007/s00704-006-0204-1.

Dickinson R E, Henderson-Sellers A and Kennedy P J 1993 Biosphere-atmosphere transfer scheme (BATS) version 1e as coupled to the NCAR community climate model, Tech. Rep., National Center for Atmospheric Research.

Dickinson R E 1984 Climate Processes and Climate Sensitivity (Geophys. Monogr. 29; Maurice Ewing Ser. 5). Am. Geophys. Union, Washington DC.

Dimri A P 2007 A study of mean winter circulation characteristics and energetic over the southeastern Asia; Pure Appl. Geophys. 164 1081-1106.

Dimri A P and Ganju A 2007 Wintertime seasonal simulation over western Himalayas using RegCM3; Pure Appl. Geophys. 164 1733-1746.

Dimri A P 2008 Impact of subgrid scheme on topography and landuse for better regional scale simulation of meteorological variable over the western Himalayas; Clim. Dyn. 32 565-574.

Dimri A P and Mohanty U C 2009 Simulation of mesoscale features associated with intense western disturbances over western Himalayas; Meteorol. Appl. 16 289-308.

Dimri A P and Niyogi D 2012 Regional climate model application at subgrid scale on Indian winter monsoon over the western Himalayas; Int. J. Climatol., doi: $10.1002 /$ joc. 3584 .

Giorgi F and Coppola E 2007 European climate-change oscillation (ECO); Geophys. Res. Lett. 34 L21703, doi: 10.1029/2007GL031223.

Goswami B N and Ajaya Mohan R S 2001 Intra-seasonal oscillations and inter-annual variability of the Indian summer monsoon; J. Climate 14 1180-1198.

Grell G 1993 Prognostic evaluation of assumptions used by cumulus parameterizations; Mon. Wea. Rev. $121764-$ 787.

Grell G, Dudhia J and Stauffer D 1994 A description of the fifth generation Penn state/NCAR Mesoscale Model (MM5); NCARTN-398+STR, NCAR Technical note. 
Hartmann D L and Michelsen M L 1989 Intraseasonal periodicities in Indian rainfall; J. Atmos. Sci. 46(18) 2838 2862.

Holtslag A A M and Boville B A 1993 Local versus nonlocal boundary-layer diffusion in a Global Climate Model; J. Clim. 6 1825-1842.

Im E S, Jung I W and Bae D H 2010 The temporal and spatial structure of recent and future trends in extreme indices over Korea from a regional climate projection; Int. J. Climatol. 31 72-86, doi: 10.1002/joc.2063.

Kanamitsu M, Ebisuzaki W and coauthors 2004 NCEPDOE AMIP-II reanalysis (R-2); Bull. Am. Meteorol. Soc. 83 1631-1643.

Kiehl J T, Hack J J, Bonan G B, Boville B A, Williamson D L and Rasch P J 1998 The National Center for Atmospheric Research Community Climate Model: CCM3; Am. Meteorol. Soc., pp. 1131-1149.

Kriplani R H, Kulkarni A and Sabade S S 2003 Western Himalayan snow cover and Indian monsoon precipitation: A re-examination with INSAT and NCEP/NCARNCEPNCAR data; Theor. Appl. Climatol. 74 1-18, doi: 10. 1007/s00704-002-0699-z.

Krishnamurthy V and Shukla J 2000 Intra-seasonal and interannual variability of precipitation over India; J. Clim. 13 4366-4377.

Kumar P and Kriplani R H 2004 Northeast monsoon precipitation variability over south peninsular India vis-a-vis the Indian Ocean dipole mode; Int. J. Climatol. 24 12671282, doi: 10.1002/joc.1071.

Kumar P, Rupa Kuamar K, Rajeevan M and Sahai A K 2007 On the recent strengthening of the relationship between ENSO and northeast monsoon precipitation over India; Clim. Dyn. 28 649, doi: 10.1007/s00382-006-0210-0.

Lang J T and Barros A P 2004 Winter storms in the central Himalayas; J. Meteorol. Soc. Japan 82 829-844.

Lucas-Picher P, Christensen J H, Saeed F, Kumar P, Asharaf S, Ahrens B, Wiltshire A J, Jacob D and Hagemann S 2011 Can regional climate models represent the Indian monsoon?; J. Hydrometeorol. 12(5) 849-868.

Mearns L O, Giorgi F, Shields Brodeur C and McDaniel L 1995 Analysis of the variability of daily precipitation in a nested modeling experiment: Comparison with observations and 2XCO2 results; Glob. Planet. Change 10 $55-78$.

Mitchell T D and Jones P D 2005 An improved method of constructing a database of monthly climate observations and associated high-resolution grids; Int. J. Climatol. $\mathbf{2 5}$ 693-712.

Mooley D A and Parthasarathy B 1984 Fluctuations in allIndia summer monsoon precipitation during 1871-1978; Clim. Change 6 287-301.

Pal J S, Giorgi F and Bi X 2004 Consistency of recent European summer precipitation trends and extremes with future regional climate projections; Geophys. Res. Lett. 31 L13202, doi: 10.1029/2004GL019836.

Pal J and Coauthors 2007 Regional Climate Modelling for the Developing World: The ICTP RegCM3 and RegCNET; Bull. Am. Meteor. Soc. 88(9) 1-42.

Pattnayak K C, Panda S K and Dash S K 2013 Comparative study of regional rainfall characteristics simulated by RegCM3 and recorded by IMD; Glob. Planet. Change 106 111-122.

Rajeevan M and Bhate J 2008 A high resolution daily gridded precipitation dataset (1971-2005) for mesoscale meteorological studies; Curr. Sci. 96 558-562.

Ratnam J V, Giorgi F, Kaginalkar A and Cozzini S 2009 Simulation of the Indian monsoon using the RegCM3ROMS regional coupled model; Clim. Dyn. 33 119-139.

Ratna S B, Sikka D R, Dalvi M and Venkata Ratnam J 2010 Dynamical simulation of Indian summer monsoon circulation, precipitation and its interannual variability using a high resolution atmospheric general circulation model; Int. J. Climatol., doi: 10.1002/joc.2202.

Rayner N A, Horton E B, Parker D E, Folland C K and Hackett R B 1996 Version 2.2 of the Global Sea Ice and Sea Surface Temperature data set, 1903-1994, Climate Research Technical note no. 74

Shekhar M S and Dash S K 2005 Effect of Tibetan spring snow on the Indian summer monsoon circulation and associated rainfall; Curr. Sci. 88 1840-1844.

Seth A, Raschur S A, Camargo S J, Qian J and Pal J S 2007 RegCM3 regional climatologies for South American using reanalysis and ECHAM global model driving fields; Clim. Dyn. 28 461-480, doi: 10.1007/s00382-006-0191-z.

Sylla M B, Coppola E, Mariotti L, Giorgi F, Ruti P M, EllAquilla A and Bi X 2009a Multiyear simulation of the African climate using a regional climate model (RegCM3) with the high resolution ERA-interim reanalysis; Clim. Dyn. 35 231-247, doi: 10.1007/s00382-009-0613-9.

Sylla M B, dellÁquila A, Ruti P M and Giorgu F 2009b Simulation of the intraseasonal and the interannual variability of rainfall over west Africa with RegCM3 during the monsoon period; Int. J. Climatol. 30 1865-1883.

Wang B, Wu R and Lau K M 2001 Interannual variability of the Asian summer monsoon: Contrast between the Indian and the western north Pacific-east Asian monsoons; $J$. Clim. 14 4073-4090.

Yadav R K 2012 Emerging role of Indian ocean on Indain northeast monsoon; Clim. Dyn. 41 105-116.

Yatagai A, Arakawa O and Kamiguchi K et al. 2009 A 44year gridded precipitation data set for Asia based on a dense network of rain gauges.

Zeng X, Zhao M and Dickinson R E 1997 Intercomparison of bulk aerodynamic algorithms for the computation of sea surface fluxes using TOGA COARE and TAO data; J. Clim. $112628-2644$. 